\title{
Functional hypotheses of the coeruleocortical noradrenergic projection: A review of recent experimentation and theory
}

\author{
T. W. ROBBINS, B. J. EVERITT, and B. J. COLE \\ University of Cambridge, Cambridge, England \\ T. ARCHER \\ Research and Development Laboratories, Astra Läkemedel AB, Södertälje, Sweden
}

and

\author{
A. MOHAMMED \\ University of Uppsala, Uppsala, Sweden
}

\begin{abstract}
The behavioral function of the coeruleocortical system and the hypotheses implicating its role in mediating selective attention and behavioral inhibition to anxiogenic cues are evaluated. The diverse pattern of results produced by lesions induced by 6-hydroxydopamine on a variety of tasks (appetitive conditional discrimination, nonreversal shift, blocking, latent inhibition, distraction, taste aversion, neophobia, and conditioned emotional response) are integrated to achieve a tentative hypothesis of coeruleocortical noradrenergic function.
\end{abstract}

There has been enormous interest in the functions of the nucleus locus coeruleus (LC) and its projections to the cortex via the dorsal noradrenergic bundle (DNAB) from several neurobiological perspectives. Although the nature of the afferents to the LC and the precise organization of the DNAB are still a matter for debate, it is perhaps of some functional significance that a single cell body can give rise to both ascending and descending axons innervating regions as diverse as the neocortex, hippocampus, cerebellum, and spinal cord. These peculiar features of organization suggest, for want of a better term, a rather "general" function whereby messages relayed to at least a proportion of noradrenergic (NA) cell bodies would result in the transmission of information to widespread regions, thereby influencing the special forms of processing occurring there.

Although such general considerations imply rather nonspecific functions for the LC, we should like to avoid the temptation of assuming simply that this implies a role in nonspecific processes along the lines of the maintenance of cortical arousal by the reticular formation suggested originally by Hebb, Lindsley, and others. Recent neu-

This article is based on a roundtable discussion held at the European Brain and Behavior Society Workshop on Brain Plasticity, Learning and Memory held August 30-September 1, 1984, in Strasbourg, France.

Most of the experiments reported here were supported by the Medical Research Council (United Kingdom). B. J. C. holds an MRC studentship. We thank G. H. Jones and C. de la Riva for technical assistance, T. Kelly for typing the manuscript, and Raith Overhill for the illustrations. Address correspondence to T. W. Robbins, Department of Experimental Psychology, University of Cambridge, Downing Street, Cambridge CB2 3EB, England. roanatomical evidence, much of it involving immunocytochemical methods, has shown that there are several neurochemically distinct nonspecific ascending projections from regions formerly included within the reticular formation; these include, in addition to noradrenergic ones, serotonergic, dopaminergic, and, more recently, cholinergic neurons. Comparison of the cortical targets of these projections reveals that they differ not only in the regions but also in the precise cortical layers that are innervated (Geffen, Clark, \& Geffen, 1984). Thus, for example, noradrenergic and serotonergic projections innervate complementary layers of the visual cortex (e.g., layers VI and IV, respectively) (Morrison \& Magistretti, 1983). This implies that these two projections, however nonspecific their functions, are actually mediating different types of influence upon visual cortical function.

Electrophysiological analyses have promised to separate the influences of these various cortical projections by recording from single neurons and examining the effects of manipulating the ascending systems. Thus, for example, Segal and Bloom (1976) demonstrated that both electrical stimulation of the LC and microiontophoresis of noradrenaline (NA) onto the pyramidal cells of the hippocampus enhanced the inhibitory effect of an auditory tone on hippocampal firing, or, alternatively, enhanced the excitatory effect of the same stimulus when predictive of food. These observations were taken to suggest that activity with the coeruleocortical system enhanced the signal-to-noise $(\mathrm{S} / \mathrm{N})$ ratio of the evoked responses to salient environmental stimuli. Foote, Friedman, and Oliver (1975) also showed that microiontophoresis of NA 
onto cells in the auditory cortex of the squirrel monkey changed the pattern of firing to species-specific vocalizations such that NA generally inhibited firing, but did so to a greater extent for the background firing rate. Analogous data have accrued from studies of somatosensory cortex (Waterhouse \& Woodward, 1980) and visual cortex (Kasamatsu \& Heggelund, 1982). Thus, the effect of NA applied to the neocortex extends over at least three sensory modalities and seems to enhance responses to stimuli conveyed to the specific cortical region by direct thalamic sensory projections. In general, this is consonant with the notion of enhanced $\mathrm{S} / \mathrm{N}$ ratio as a major effect of coeruleal noradrenergic transmission.

The crucial issue is, what behavioral or physiological functions do these changes in firing imply? One suggestion has been that release of cortical NA provides the reinforcing impact necessary for learning to occur (Crow, 1968; Kety, 1970), a hypothesis with as yet limited experimental support (see Mason \& Iversen, 1979). Some of the main support has, in fact, derived from evidence suggesting a more general role for cortical NA in neuronal plasticity (Kasamatsu, 1983; Sutherland, Kolb, Whishaw, \& Becker, 1982) or in biological contexts, such as the impact of olfactory cues on reproductive functions in mice (Keverne \& de la Riva, 1982) or imprinting in chicks (Davies, McCabe, \& Horn, 1985).

An alternative hypothesis, quite closely modeled upon the neurophysiological data, is that the LC is involved in selective attention, with enhanced activity in the system at terminal regions reducing the effects of stimuli that lack salience and enabling the organism to process certain events while ignoring others (Mason \& Iversen, 1979). This, for example, would explain the observations of Segal and Bloom (1976) that stimulation of the LC enhanced the hippocampal evoked response to a tone when paired with food, but reduced it when the stimulus was no longer novel and had no additional significance.

The evidence for the attentional hypothesis was based initially upon the behavioral effects of selective lesions of the DNAB, using the neurotoxin 6-hydroxydopamine (6-OHDA). When injected into an appropriate site along the trajectory of the DNAB, this treatment produced almost total depletion of cortical and hippocampal NA. Rats treated in this way showed no deficits in acquiring a runway or operant response for food, but were slower to extinguish these responses when food was withdrawn (Mason \& Iversen, 1979). This was interpreted, according to the Sutherland and Mackintosh (1971) model of selective attention, to mean that the rats with DNAB lesions had attended to more cues during learning and had thus formed more stimulus-reinforcer associations, which, as a result, took longer to extinguish. The attentional hypothesis makes other, more specific, predictions, some of which have been tested with the somewhat conflicting results to be detailed below.

The main rival to the attentional hypothesis is the theory that the coeruleocortical system is part of a mechanism mediating behavior inhibition to anxiogenic cues, which are hypothesized to include signals of punishment, nonreward, and novelty (Gray, 1982). This hypothesis, among other predictions, can account for the retarded extinction reported following DNAB lesions as a reduction in the effect of "frustrative" nonreward. A related proposal has been made by Redmond (1979).

These behavioral hypotheses of functions of the LC are important because they not only provide a test case for assessing the appropriateness of formulating functional hypotheses in the context of detailed neurobiological information, but also may guide the collection of further electrophysiological and neurochemical data by specifying suitable experimental conditions for optimizing this enterprise. Thus, for example, the idea that the LC might be active under operationally defined conditions generating anxiety suggests that it should be studied specifically under such conditions.

The purpose of this article is to reconsider the behavioral hypotheses of LC function and to review the problems we have had in testing them, not only from the point of view of behavioral interpretation, but also because of technical and methodological difficulties which are often not taken into account. In order to review some of our data and to also include previously unpublished results, our review of the published literature is necessarily selective. We began with the intention of providing definitive tests of the attentional hypothesis, but, as will be seen, we have obtained results which bear on most of the major alternative hypotheses. Finally, we will attempt to suggest a new framework for understanding the LC function, a framework which in part interrelates some of the existing hypotheses.

\section{SELECTIVE ATTENTION HYPOTHESIS}

One of the most important papers supporting the attentional hypothesis has been that of Mason and Lin (1980), who used several paradigms for evaluating selective attention in animals, including nonreversal shift and latent inhibition. In the nonreversal shift paradigm, the extent to which animals have attended to previously irrelevant stimuli (i.e., those unpredictive of reward) is measured by subsequently making the stimuli relevant (i.e., predictive of reward). This procedure should be advantageous to a rat unable to ignore these formerly irrelevant stimuli, and hence would lead to a faster acquisition of response to them. Thus, under certain conditions, better acquisition would be predicted in rats with DNAB lesions. This, of course, is a particularly strong prediction because it should immediately rule out the possibilities that the lesioned rats are impaired motivationally, or in sensory or motor function, or indeed in their basic capacity to form associations. Mason and Lin (1980), in fact, found faster nonreversal shift in DNAB-lesioned rats, but they studied only shifting from a visual to a spatial dimension. As the DNAB rats were impaired in acquiring the simultaneous visual discrimination, this might merely reflect a basic preference to attend to spatial dimensions, rather than an inability to screen out irrelevant dimensions. Moreover, 
Pisa and Fibiger (1983b) failed to replicate the enhanced shifting by DNAB-lesioned rats from visual to position cues.

\section{Acquisition of Appetitive \\ Conditional Discrimination}

In our attempt to design a nonreversal shift task with symmetrical dimensions, we utilized a discrimination of temporal frequency ("slow" vs. "fast") in either the auditory (tone) or visual (light) modalities (Everitt, Robbins, Gaskin, \& Fray, 1983; Robbins et al., 1982). In the nonreversal shift version of the task, the two modalities were presented simultaneously in a compound stimulus, one element of which was correlated with reward (contingent upon the correct choice), the other one of which was not (see Robbins et al., 1982).

However, it was difficult to test the hypothesis that DNAB-lesioned rats would show faster nonreversal shift, because they were impaired even in the acquisition of the basic discrimination, compared to control groups with sham lesions or 6-OHDA lesions of the mesolimbic dopamine projection to the nucleus accumbens (Robbins et al., 1982). Although this basic impairment in acquisition made difficult any conclusions about the effects of DNAB lesions on nonreversal shift, it could in principle have been turned to advantage if the deficit was present only when both modalities were present, because it would imply that the presence of such explicitly irrelevant stimuli in a second modality would command greater attention than normal in DNAB-lesioned rats, and hence would retard acquisition. The obvious test of this hypothesis was to study acquisition of the temporal frequency discrimination when only the single relevant modality was present. In several experiments (Everitt et al., 1983; Robbins et al., 1982) we have found that, even under these conditions, rats with 6-OHDA lesions of the DNAB are impaired in reaching a stringent criterion of acquisition for either the visual or auditory form of the task, compared with sham-operated controls. A typical example of such a deficit for the visual version of the task is shown in the previously unpublished data shown in Figure 1 (Everitt, Robbins, Fray, \& Gaskin, 1982). This shows the cumulative mean sessions to reach successive criteria of acquisition, starting at $59 \%$, the point at which performance begins to be significantly different from chance. An exactly parallel picture was found for errors to criterion (data not shown). Statistical analysis reveals that the difference between the groups becomes significant only at the most stringent criteria of acquisition. However, in considering the sessions (or errors made) in moving between the successive criteria (i.e., from chance to $59 \%$, from $59 \%$ to $67 \%$, etc.) it is apparent that the DNAB-lesioned group make more errors (or take more sessions) without respect to transition to a particular criterion. This point is perhaps better shown in Figure 2, which summarizes the data from 23 DNABlesioned rats and 21 sham-operated controls, collated from three experiments on the visual discrimination task in the form of backward learning curves (hence showing mean

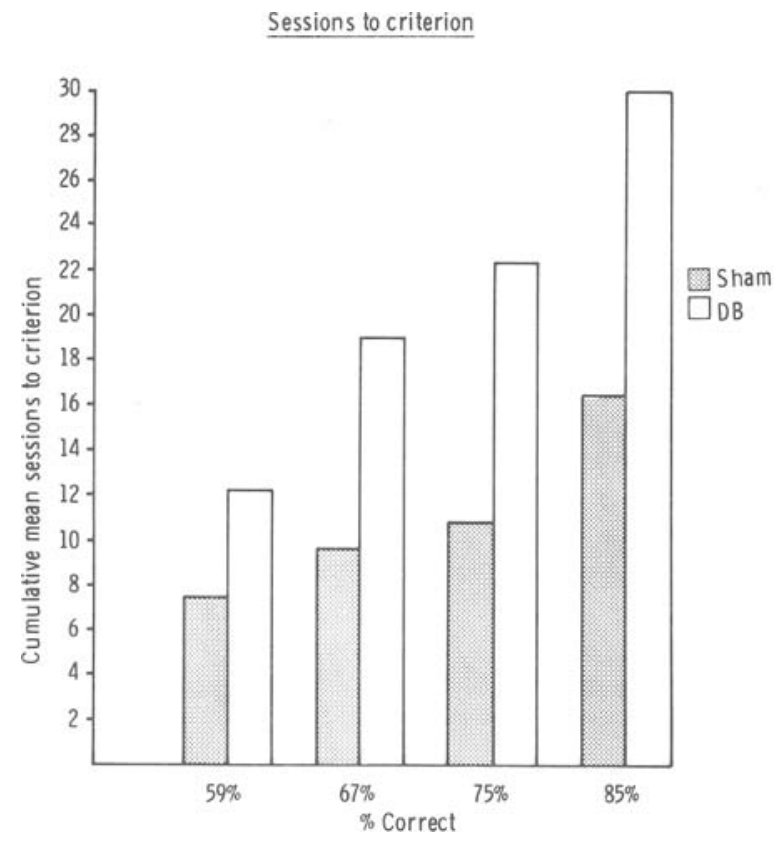

Figure 1. Sessions to successive criteria of acquisition of DNABlesioned rats (DB, unshaded) and sham-operated controls on the visual version of the conditional appetitive discrimination of temporal frequency described by Everitt et al. (1983). Fifty-nine percent is better than chance performance for 128 trials/session. The data are from an unpublished replication by Everitt et al. (1982) of earlier results of Everitt et al. (1983).

errors made on each session backward from the one at which the $85 \%$ criterion was attained). Regression lines are fitted in Figure 2 to the sensibly linear portion of the plots beginning from Session 2; these account for a large proportion of the variance (about $90 \%$ ) and also differ significantly $[\mathrm{F}(1,504)=14.41, \mathrm{p}<.01]$, with the slope for the DNAB group being more shallow. These results pose many questions, which perhaps need some consideration here.

First, what is the behavioral interpretation of such results? At the most basic level, it could perhaps be asked whether the DNAB lesion affected a motivational variable or even the perceptual capacity of the animals to distinguish the stimuli, rather than affecting acquisition directly. However, a control experiment in which rats were pretrained to different levels prior to surgery seemed to rule out these possibilities. Those animals that reached the $85 \%$ criterion exhibited a transient, mild impairment in performance of the discrimination; those that reached the $75 \%$ criterion showed no deficit and continued to make progress toward the $85 \%$ level. However, those rats that had been pretrained prior to surgery but had not reached better than chance performance were impaired, relative to sham-operated controls, when tested postsurgery-thus exhibiting a deficit in acquisition (Everitt et al., 1983) (see Figure 3). We must also be careful to consider whether any other unconditioned effects of DNAB lesions impair acquisition indirectly by altering performance variables, 


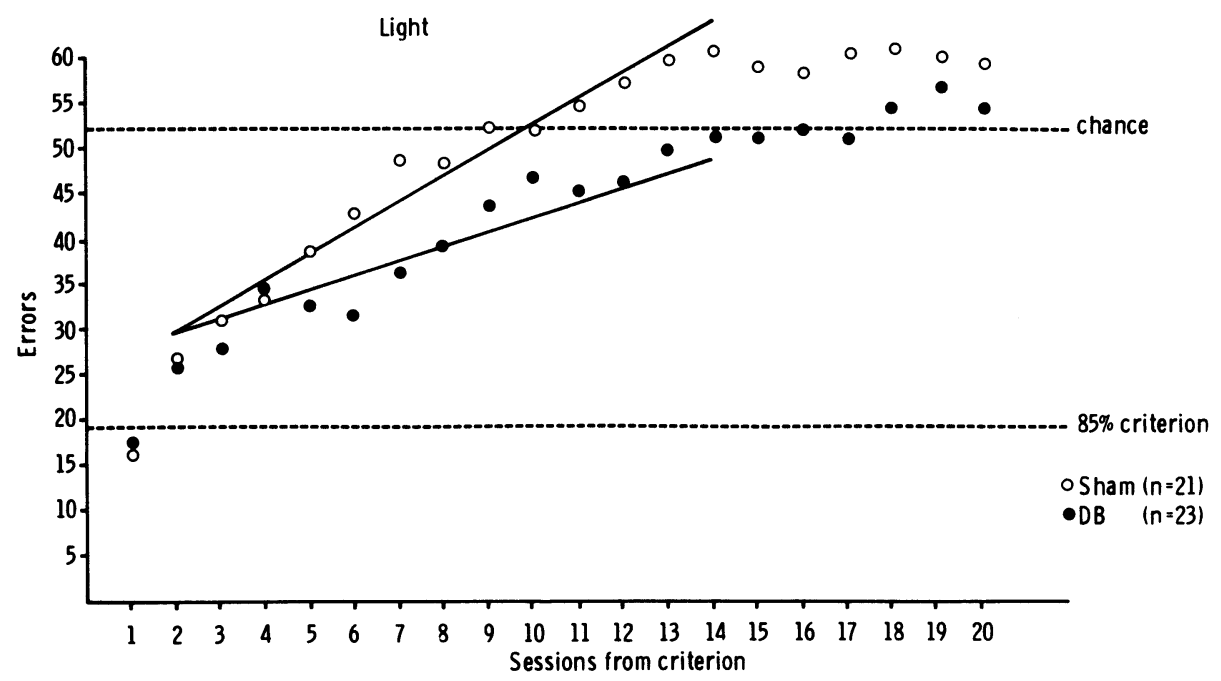

Figure 2. Backward learning curves from the $85 \%$ ( $\leq 19$ errors per 128 trials) criterion of the temporal frequency discrimination for DNAB-lesioned (DB) and sham-operated control rats, totaled across three separate replications. The DB (lesioned) group has a significantly shallower slope $(y=1.60 x$ $+27.76)$ following fitting of lines by linear regression than that of the sham group $(y=2.84 x+26.69)$. (Everitt et al., 1982)

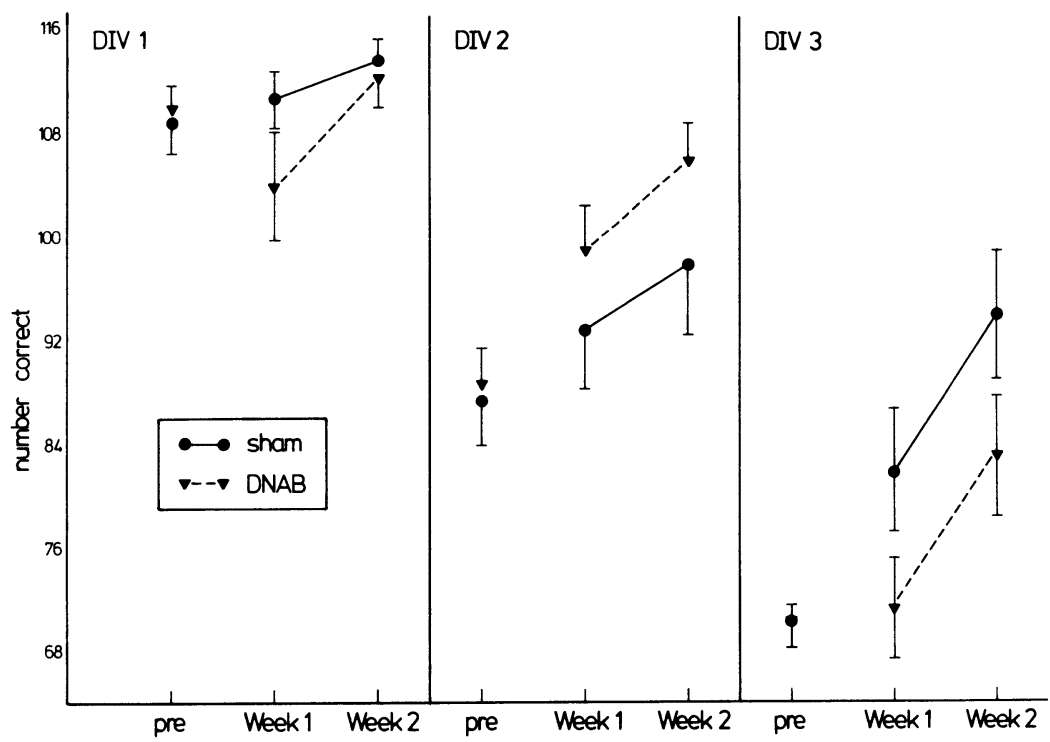

Figure 3. Effects of DNAB lesions on the performance (number correct out of 128) of previously trained temporal discriminations to varying degrees of accuracy. DIV 1 = rats attaining the $85 \%$ criterion presurgery. DIV 2 = rats attaining better than chance but worse than $85 \%$ criterion presurgery. DIV 3 = rats failing to attain better than chance performance presurgery. The DNAB-lesioned groups were significantly impaired only over Postoperative Weeks 1 and 2 in DIV 3. Each week consisted of five sessions for each rat. Data redrawn from Everitt et al. (1983).

as appears to be the case for certain simple runway, discrimination, or delayed alternation deficits reported to result from DNAB lesions (see Owen, Boarder, Gray, \& Fillenz, 1982; Pisa \& Fibiger, 1983a, 1983b). However, it is difficult to see, either from the design of our discrimination task or from the pattern of results obtained, how such factors could have influenced acquisition (see also Everitt et al., 1983).
Second, if it can be assumed that the deficit is largely present during acquisition, why have so many other experiments utilizing the same preparation found negative results when studying other forms of conditioning, for example, operant lever pressing under continuous reinforcement (CRF) schedules or conditioned taste aversion (CTA) (see Mason \& Iverson, 1979), or simple simultaneous brightness, positional, or body-turn discrimination or 
delayed alternation in mazes (Pisa \& Fibiger, 1983a, 1983b)? The obvious answer is that the task is behaviorally more demanding than these other forms of conditioningas seen from the fact that the discrimination takes many sessions to acquire. Less obvious is what makes it so difficult. Technically, the discrimination is a GO-GO conditional discrimination, rather than a simple simultaneous or successive task (see Mackintosh, 1983), and it may be that such conditional tasks are especially revealing of hippocampal or neocortical dysfunction. However, as will be seen, other conditional discrimination tasks can be acquired quite normally by DNAB-lesioned rats, and so perhaps the nature of the discrimination itself should be explored further. Although correctly designated as a discrimination of temporal frequency, the task was not explicitly intended to test temporal discrimination, and more specific tests of temporal processing, along the lines of the recent study by Meck, Church, and Olton (1984), should perhaps be designed.

Finally, what is the theoretical significance of the results? First, it is not altogether clear that the finding of an impairment constitutes evidence against the attentional hypothesis, for it can always be maintained that the impairment results from attentional deficits which cause the relevant events to fail to reach the associative mechanisms, rather than from disruption in the associative mechanisms themselves. However, one fact, at least, seems inconsistent with a simple attentional hypothesis. In practice, $100 \%$ performance of the discrimination is seldom, if ever, attained (85\% correct tends to be the mean asymptotic level of performance), and the most obvious explanation of this is that a certain number of choices are incorrectly made because of a failure to attend to the discriminanda. Thus, it is surprising, from the standpoint of the attentional hypothesis, that the DNAB-lesioned rats reach and maintain the same asymptotic level of performance as sham-operated controls.

An alternative perspective, based on the anxiety hypothesis, would be that the deficit arose because of a reduction in the effect of nonreward, errors being more gradually eliminated as a result. The problem with this interpretation is that no differences were found in the rate of extinction between DNAB-lesioned and sham-operated controls in the conditional discrimination task (Everitt et al., 1983). Furthermore, there have been several failures to replicate the resistance-to-extinction effect (e.g., Tombaugh, Pappas, Roberts, Vickers, \& Szostak, 1983 ), including work in our own laboratory (Robbins \& Everitt, 1982).

The result, of course, is quite good news for the learning hypothesis of coeruleal function, since it predicts deficits in acquisition. This hypothesis could then maintain that other failures to observe acquisition impairments resulted from the extensive pattern of compensatory changes, including the induction of tyrosine hydroxylase in surviving NA neurons (Acheson, Zigmond, \& Stricker, 1980 ) and elevations in $\beta$-receptor density (Harik et al., 1981; U'Prichard, Reisine, Mason, Fibiger, \& Yamamura, 1980) known to occur following 6-OHDA le- sions of the DNAB. Indeed, in collaboration with Dooley (Dooley, Jones, Cole, \& Robbins, 1984), we have found that 6-OHDA lesions of the DNAB result in elevations in $\beta$-receptor density in the neocortex which can still be present as long as 13 months after surgery (see Table 1 ). However, the possibility that sprouting and collateral growth of neurons are an important part of the compensatory response can presumably be ruled out, because the 6-OHDA lesions of the DNAB are made in the midbrain, rather than in the very distant terminal regions. The learning hypothesis could also cite other reports of acquisition failure, for example, in acquiring mazes, in simultaneous and successive visual discriminations, and in active avoidance (when combined with adrenalectomy; see Robbins et al., 1982), although the many negative results also have to be taken into account.

In resisting this interpretation of the results, one could perhaps point out that the deficit is not definitively linked to reduced activity of the LC. It is even possible that the compensatory changes described above produce deficits, perhaps by inducing functional overactivity of the system. Another potential problem is that the 6-OHDA lesion of the DNAB is far from precise. Although the general neuroanatomical and neurochemical specificity of the 6-OHDA lesions has been convincingly demonstrated (Mason \& Fibiger, 1979), inspection of typical regional assay data for NA levels (see Table 2) indicates that there is a substantial hypothalamic depletion (generally varying from $40 \%$ to $70 \%$ ) which accompanies the profound neocortical and hippocampal loss. Since the LC, via the DNAB, contributes only about $20 \%$ of the hypothalamic NA projection, it seems likely that the 6-OHDA place-

Table 1

$\beta$-Adrenoceptor Binding Following 6-OHDA Lesions of DNAB at Different Times After Surgery

\begin{tabular}{cccc}
\hline & DNAB & Sham & $\begin{array}{c}\text { \% Neocortical } \\
\text { NA Depletion }\end{array}$ \\
\hline 1 Month & $\begin{array}{c}83.0 \pm 2.9 \\
(\mathrm{n}=6)\end{array}$ & $\begin{array}{c}57.8 \pm 2.8 \\
(\mathrm{n}=6)\end{array}$ & $\begin{array}{c}100 \\
\text { (trace })\end{array}$ \\
3 Months & $\begin{array}{c}83.5 \pm 3.8 \\
(\mathrm{n}=6)\end{array}$ & $\begin{array}{c}57.2 \pm 3.0 \\
(\mathrm{n}=6)\end{array}$ & 89.0 \\
13 Months & $\begin{array}{c}69.3 \pm 5.2 * \\
(\mathrm{n}=10)\end{array}$ & $\begin{array}{c}62.5 \pm 3.2 \\
(\mathrm{n}=6)\end{array}$ & 89.1 \\
&
\end{tabular}

Note-Values shown are mean $\pm S E$ fmol/mg protein. The right-hand column shows percent depletion of cortical NA in the 6-OHDA group, compared with sham controls. $\beta_{1}$-receptor binding was measured using $\left[{ }^{\beta} \mathrm{H}\right]-\mathrm{DHA}$ as the ligand. The assay involved a 30 -min incubation at $22^{\circ} \mathrm{C}$ of $1.6 \mathrm{ml}$ of $50 \mathrm{mM}$ Tris/HCl buffer ( $p H$ 8.0), $100 \mu \mathrm{l}$ of membrane suspension (300 $\mu \mathrm{g}$ of protein), $200 \mu \mathrm{l}$ of either buffer (for total binding) or a solution containing competing drug and $100 \mu$ l of the ligand, $0.5 \mathrm{nM}$. Nonspecific binding was estimated with $1 \mu M$ alprenolol. Incubations were terminated by rapid filtration through CFC glass fiber filters, which were rinsed three times with $4 \mathrm{ml}$ of ice-cold buffer and transferred to vials for scintillaton counting. No Scatchard analysis was performed, so the possibility of changes in receptor affinity following DNAB lesions was not assessed. *Note heterogeneity in 13-month group. One subgroup $(n=5)$, with almost total cortical NA depletion (mean = $0.004 \mathrm{ng} / \mathrm{mg}$ ), had still-elevated $\beta$-binding (mean $=83.6 \pm 3.6 \mathrm{fmol} / \mathrm{mg}$ protein). The other subgroup $(n=5)$, with less profound cortical $N A$ depletion (mean $=0.090 \mathrm{ng} / \mathrm{mg}$ ), had a mean value for binding of only $55.0 \pm 1.3 \mathrm{fmol} / \mathrm{mg}$ protein (Dooley et al., 1984). 
Table 2

Neurochemical Assay of 6-OHDA Lesions of DNAB

\begin{tabular}{llccc}
\hline \multicolumn{1}{c}{ Experiments } & Condition & $\mathrm{n}$ & Neocortex NA & Hypothalamus NA \\
\hline Nonreversal shift & DNAB & 16 & $0.037 \pm 0.002$ & $1.656 \pm 0.025$ \\
& sham & 18 & $0.492 \pm 0.030$ & $3.183 \pm 0.210$ \\
& & $\%$ depletion & 92.5 & 48.0 \\
Latent inhibition & DNAB & 23 & $0.037 \pm 0.008$ & $1.278 \pm 0.203$ \\
& sham & 20 & $0.446 \pm 0.026$ & $2.451 \pm 0.131$ \\
Blocking & & $\%$ depletion & 91.6 & 48.0 \\
& DNAB & 17 & $0.039 \pm 0.024$ & $0.797 \pm 0.105$ \\
& sham & 14 & $0.441 \pm 0.026$ & $2.590 \pm 0.200$ \\
Neophobia/13-month postsurgery & DNAB & $\%$ depletion & 91.0 & 69.0 \\
temporal frequency discrimination & sham & 8 & $0.038 \pm 0.097$ & $1.072 \pm 0.101$ \\
& & $\%$ depletion & $0.349 \pm 0.034$ & $1.927 \pm 0.111$ \\
\hline
\end{tabular}

Note-This table summarizes regional neurochemical assay data involving high-performance liquid chromatography with electrochemical detection for previously unpublished experiments, the behavioral results of which are reported following 6-OHDA lesions of the DNAB. The parameters of the lesion coordinates and surgical details are to be found in Carli et al. (1983), and an account of the assay procedure in Everitt et al. (1983). Values provided are mean levels of NA in neocortex or hypothalamus expressed as ng/mg concentration wet weight. All depletions shown are significant at $p<.01$. The animals were randomly selected from a larger population in the case of all experiments except for nonreversal shift. Animals with less than 50\% cortical NA depletion were excluded from this table (and from the behavioral results). This resulted in the exclusion of 2 rats from the nonreversal shift and 2 from the latent inhibition experiments. (For more detailed data on neurochemical assays, see Mason \& Iversen, 1979.) However, hippocampal NA levels are reduced by about 85\%-90\% by this treatment (see Everitt et al., 1983, and Table 4) and striatal DA levels are unaffected (e.g., nonreversal shift: anterior caudate $D A ; D N A B=9.661 \pm 0.55 ;$ sham $=9.722 \pm 0.53 \mathrm{ng} / \mathrm{mg}$ ) (see also Table 4).

ment also damages, to a variable extent, the NA pathways to the hypothalamus arising from NA cell bodies in the medulla. Indeed, it is now clear that a major proportion of $\mathrm{A} 1$ axons leave the ventral noradrenergic bundle (VNAB) in the caudal midbrain to join the DNAB (Sawchenko \& Swanson, 1981), and these will be unavoidably damaged after 6-OHDA lesions of the DNAB, leading to considerable hypothalamic NA loss. The criticism that combined damage to both DNAB and VNAB following 6-OHDA lesions possibly contributes to acquisition deficits has already been raised by Gray (1982), with particular reference to the study of Leconte and Hennevin (1981). Therefore, we have taken care to exclude a contribution to acquisition impairments of damage to lateral tegmental NA neurons, by making explicit 6-OHDA lesions of the VNAB at the level of the pons-medulla junction. This treatment, while producing a substantial ( $70 \%)$ depletion of hypothalamic NA, only slightly (20\%-30\%) depletes cortical NA (Everitt et al., 1983; Sahakian et al., 1983). As can be seen from Figure 4, which summarizes all of the individual data for errors to $85 \%$ criterion across four experiments (involving both visual and auditory forms of the task), the VNAB-lesioned group showed no significant deficit compared with the various sham and unoperated control conditions. Although there is evident heterogeneity in the parallel data provided for the DNAB-lesioned group, it is apparent that the mean value for this group differs from that of each of the other conditions. Therefore, it is unlikely that hypothalamic NA depletion contributes significantly to the deficit in discrimination learning.

Although these results demonstrate that a clear deficit follows 6-OHDA lesions of the DNAB, it is much less evident whether, by the end of the experiment, sufficient recovery had occurred to make the rats essentially " normal," with the earlier deficit merely causing them to lag behind the sham-operated controls. In other words, with such a long-term behavioral test, it is difficult to specify the temporal course of the deficit. In further experiments, described by Everitt et al. (1983), it was clear that when a group of DNAB-lesioned and sham-operated rats, having attained criterion on one version of the task involving either the auditory or visual modality, was transferred to the novel alternative modality alone, there was little evidence of successful "cross-modal transfer" of learning, but the DNAB-lesioned rats were still significantly impaired, even 6 weeks after surgery.

A more stringent test, of course, would be to take operated rats, completely naive to the behavioral task, at varying times following surgery and demonstrate, at least qualitatively, similar impairments to those seen after surgery. Such a demonstration would effectively minimize the functional importance of apparent compensatory neurochemical changes. However, it is only fair to admit that we have been unsuccessful in demonstrating impairments in acquisition of the temporal frequency discrimination in rats operated over 1 year previously and (apart from an experiment on food neophobia) not tested in the interim. One group of DNAB-lesioned rats $(n=11)$, sacrificed over 15 months after surgery, had an equivalent cortical NA depletion (about 90\%) to that seen after a much shorter period (see Table 2), and many of the rats still had elevated levels of cortical $\beta$-adrenoceptors (see Table 1) (Dooley et al., 1984). Nevertheless, this group was not significantly impaired in acquisition of the visual form of the temporal frequency discrimination-indeed, 


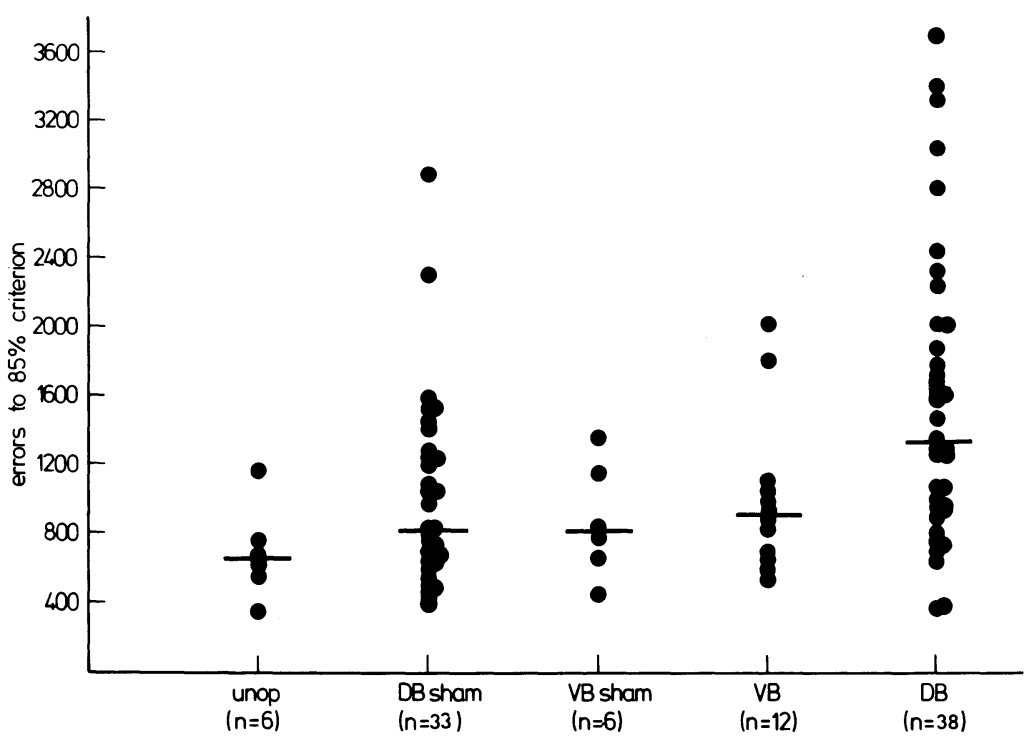

Figure 4. Summary of individual data of five experiments using either tone or light temporal frequency discriminations for errors to the $85 \%$ criterion. DB $=$ DNAB lesion, VB $=$ VNAB lesion. The number of errors for each rat is represented by a single closed circle. The horizontal lines represent the median values. (Everitt et al., 1982)

if anything, the sham-operated controls $(n=12)$ were worse (mean errors to $85 \%$ criterion, $\pm \mathrm{SE}$ : DNAB, $1,144 \pm 160$; sham, $1,412 \pm 164)$. It is noteworthy in this case that the greater age of these rats did not exacerbate the DNAB deficit-in fact, it was the aged sham-operated controls who acquired the task much more slowly than their young counterparts (cf. Figure 1). The interpretation of such results is difficult. There is no obvious indication that the DNAB deficit has been reversed by changes intrinsic to the system-if anything, $\beta$-adrenoceptor density is reduced in comparison with the levels found 3 months following surgery-although it is impossible to rule out the importance of such changes. An alternative possibility is that other neural systems have adapted by 1 year following surgery to compensate for and overcome the usual DNAB-lesion deficits.

Despite these disappointing indications that the effects of DNAB lesions are definitely antagonized by some kind of compensatory change, clearer and more illuminating evidence of longer lasting deficits has emerged from some of our recent studies using other behavioral paradigms (discussed below). However, it is apparent that the confounding problems of neuronal recovery and functional compensation are not to be underestimated in interpreting the effects of 6-OHDA lesions of the DNAB.

\section{Nonreversal Shift}

Notwithstanding the problems of interpretation inherent in studying nonreversal shifts that are provided by the DNAB acquisition deficit, we eventually implemented the nonreversal shift, as originally planned.

A total of 34 male hooded rats were trained on the compound light/tone $(\mathrm{L} / \mathrm{T})$ version of the temporal frequency discrimination. For half of the rats the visual mo- dality was relevant (fast light, " go left," slow light, "go right," or vice versa), whereas for the other half the auditory stimuli were relevant (fast tone, "go left," slow tone, "go right," or vice versa). Within each subgroup of 17 rats, 8 received 6-OHDA lesions of the DNAB and 9 were sham-operated, receiving infusions of the $0.1 \%$ ascorbate drug vehicle. The neurochemical effects of these treatments are shown in Table 2. As expected, the DNAB rats were slower to acquire both of the discriminations (mean errors to $85 \%$ criterion: sham, $\mathrm{T}=$ 1,097; $\mathrm{L}=1,016 ; 6$-OHDA, $\mathrm{T}=1,476 ; \mathrm{L}=1,480$ ), although in this particular case the deficit just failed to reach significance $[F(1,30)=3.28, p<.10]$. However, as shown in Figure 5, there were no deficits in nonreversal shift following DNAB lesions, whether the shift was from light to tone or vice versa. If anything, the DNAB group was slower to shift to the $85 \%$ criterion, at least in the condition experiencing the shift from tone relevant to light relevant (Figure 5). This negative result stands in contrast to the improved nonreversal shift performance of DNAB-lesioned rats reported by Mason and Lin (1980), but, given that the tests on shifting occurred after acquisition of the original task at 7-8 weeks following surgery, we obviously have to be cautious in interpreting the negative finding in view of the considerations detailed above. The negative conclusion does, however, agree with the results of Pisa and Fibiger (1983b) mentioned earlier.

\section{Latent Inhibition}

Mason and Lin (1980) also made a use of a second paradigm that is widely interpreted to assess the capacity of animals to ignore irrelevant stimuli, in this case made irrelevant by preexposing the stimuli in the absence of 


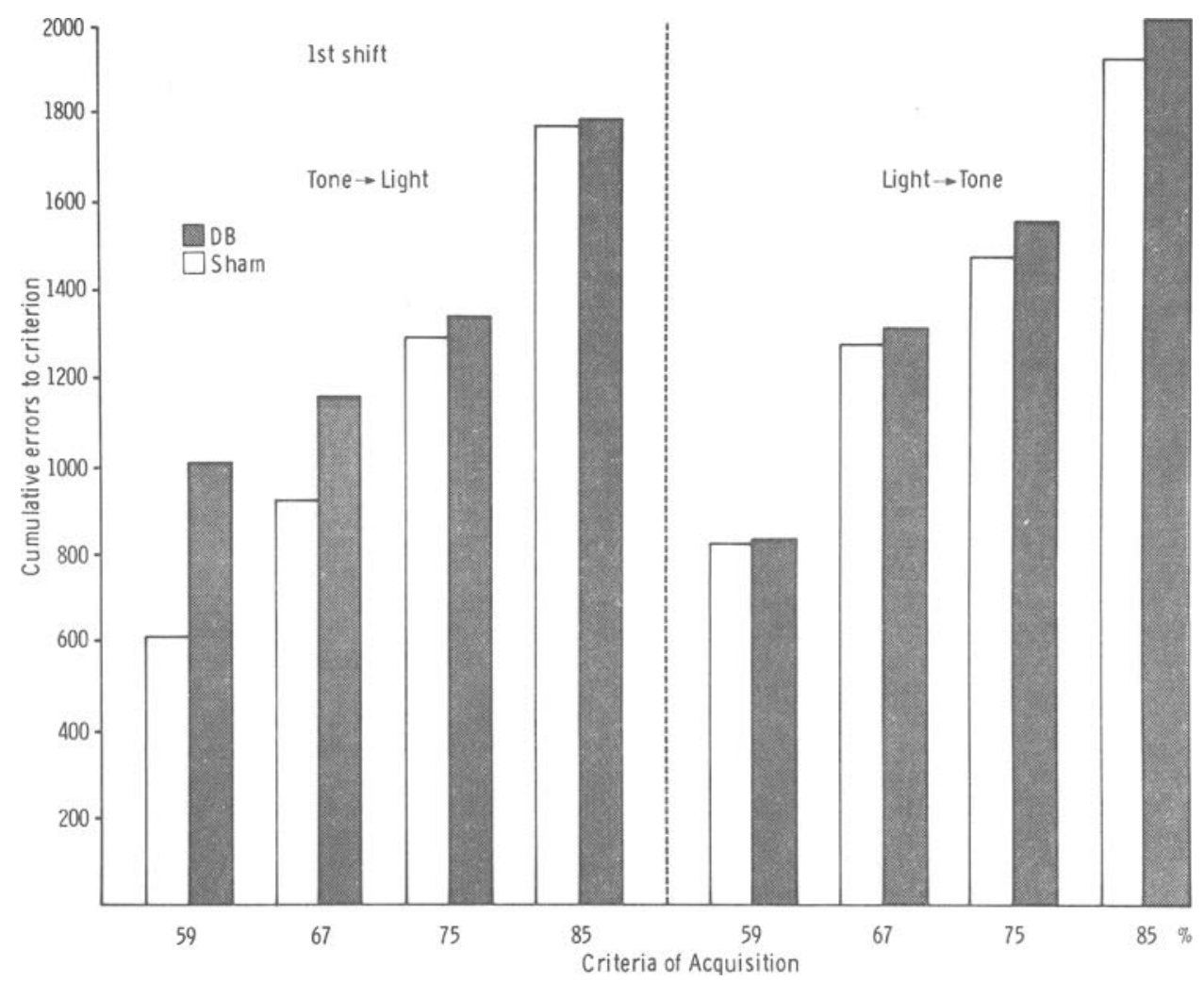

Figure 5. Failure of DNAB lesions to affect nonreversal shift either from tone to light or vice versa following pretraining on the tone/light compound temporal frequency discrimination (Robbins et al., 1982) at successive criteria of acquisition. (Robbins, Everitt, Fray, \& Gaskin, 1983)

reinforcement, with a resultant retardation of learning when they are subsequently made relevant (latent inhibition; see also Mackintosh, 1983). Once again, if the DNAB-lesioned animals have difficulty in ignoring such irrelevant stimuli, they should actually be at an advantage when the stimuli are subsequently associated with reinforcement. Indeed, Mason and Lin reported an attenuation of latent inhibition following DNAB lesions, but once more, the interpretation of the result was confounded by marked impairments in acquisition of the successive light/tone discrimination employed. Thus, the predicted facilitation of learning by the DNAB group relative to sham controls when preexposed to the discriminanda was not, in fact, observed.

When we designed an appetitive tone/light conditional discrimination task that DNAB-lesioned rats were able to solve as rapidly as controls, we found no evidence of attenuated latent inhibition by DNAB-lesioned rats (see Figure 6, reproduced from Robbins et al., 1982). Subsequently, we (Mohammed et al., 1983) replicated these observations; if the light and tone discriminanda were preexposed to the rats either 7 or 14 days following surgery, there was a strong latent inhibition effect $[F(1,56)=$ $12.4, \mathrm{p}<.001]$ when the stimuli became discriminanda in the conditioned discrimination task (relative to nonpreexposed controls). There were no differences between the sham and DNAB-lesioned groups in acquiring the task
$[F(1,56)=0.7$, n.s. $]$ and no interaction with the preexposure condition $[F(1,56)=0.03$, n.s. $]$, indicating equivalent degrees of latent inhibition in the two groups (see Tables 2 and 3).

A similar lack of effect of DNAB lesions on latent inhibition has been reported by others using aversive procedures based on conditioned suppression (Lorden, Rickert, \& Berry, 1983; Tsaltas, Preston, Rawlins, Winocur, \& Gray, 1984), except under very special circumstances (Lorden et al., 1983) that overstretch the normal theoretical interpretations of latent inhibition.

We now report an additional set of experiments (Mohammed, Järbe, Archer, Robbins, \& Everitt, 1984), in which we arrived at a similar conclusion, but by using the CTA paradigm. An added feature of these experiments was that different means were used for depleting central NA, involving the use of (1) systemic injections of 6OHDA in neonates or (2) systemic injections of the selective noradrenergic neurotoxin DSP-4 (Ross, 1976). The comparative neurochemical effects of these different ways of inducing central NA depletion are shown in Table 4. Despite the apparent similarities, it should be borne in mind that there are differences between the effects of the treatments. For example, at least soon after treatment, peripheral NA neurons are depleted in the 6-OHDA neonatal and DSP-4 groups, and these procedures also deplete spinal and cerebellar NA, unlike 6-OHDA lesions of the 


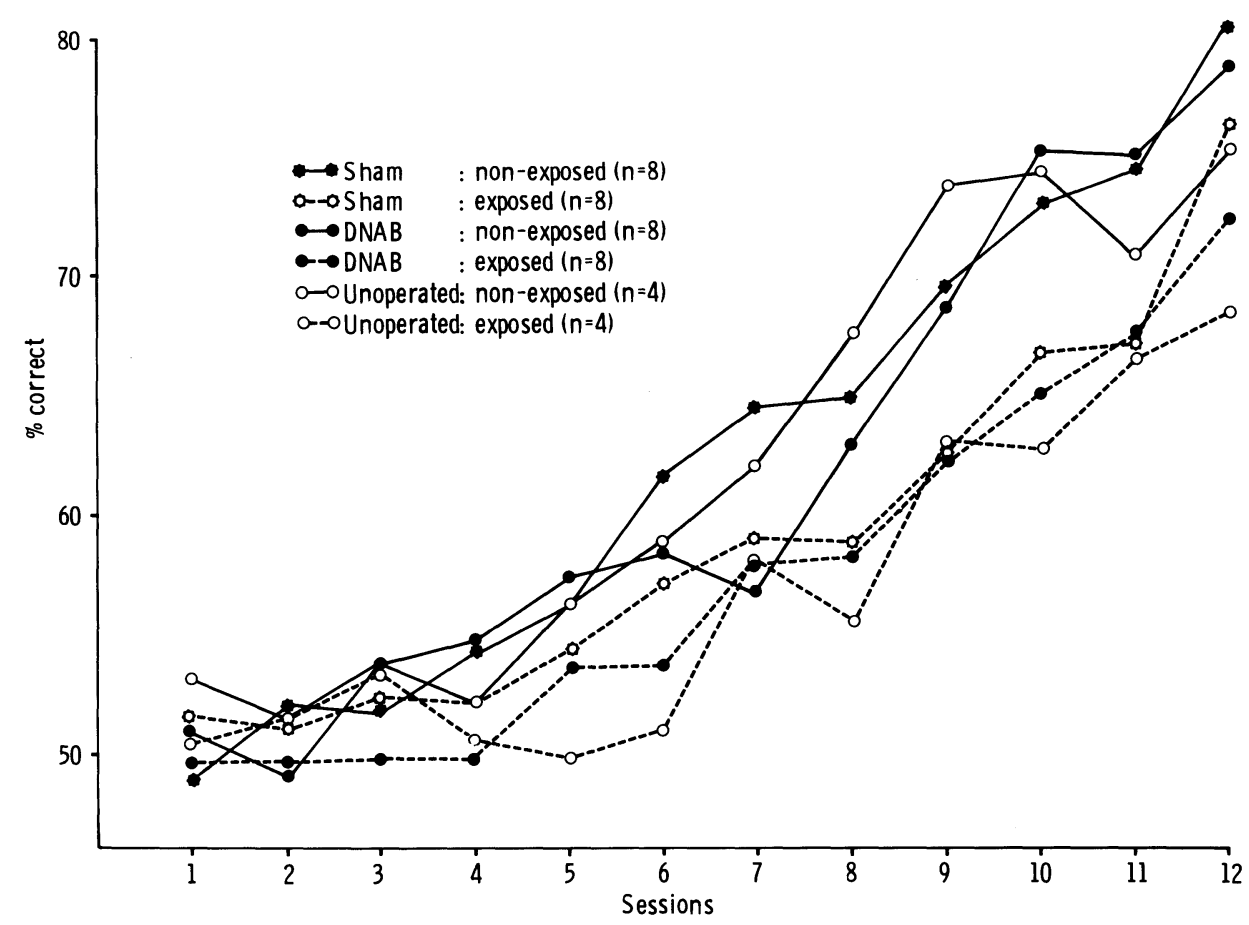

Figure 6. Failure to attenuate latent inhibition by DNAB lesions in a tone/light discrimination task. Note the strong latent inhibition effect on discrimination learning by the exposed groups. (From "The Roles of the Central Catecholamines in Attention and Learning" by Robbins et al., 1982. In M. Y. Spiegelstein and A. Levy (Eds.), Behavioral Models and the Analysis of Drug Action, Amsterdam, Elsevier. Copyright 1982 by Elsevier. Reproduced by permission.)

DNAB. Moreover, the time-course of changes in $\beta$ receptor binding seen after DSP-4 treatment (Dooley, Bittiger, Hauser, Bischoff, \& Waldmeier, 1983) is different from that we have observed (see Table 1). However, in the experiments reported here, the behavioral effects of all three manipulations were broadly similar.

Groups of treated or control rats were adapted to a water deprivation schedule and half of the groups then received preexposure to a palatable $0.2 \%$ saccharin solution. After an initially depressed response, probably resulting from neophobia, saccharin consumption slowly increased over repeated sessions. After the last of these sessions the rats received 3 daily ip injections of $0.15 \mathrm{M} \mathrm{LiCl}$ as an aversive unconditioned stimulus (US). By comparison with groups receiving $\mathrm{LiCl}$ after only a single exposure to saccharin solution, the preexposed groups showed considerably less aversive conditioning as indicated by suppression of saccharin intake-in other words, preexposure of saccharin produced a latent inhibition type of effect
(Figure 7). However, as can readily be seen in Figure 7, latent inhibition was not attenuated after any of the three forms of NA depletion. In fact, in one case (6-OHDA lesion of DNAB) there was a hint of enhanced latent inhibition. It is possible that an overexposure to saccharin might produce a negative result, essentially leading to a floor effect. However, even when the number of prior exposures was systematically varied to produce graded degees of latent inhibition, there was still no separation between NA-depleted and sham control groups (data not shown).

All of these data together lead us to arrive at a quite convincing conclusion about the negative effects of central NA depletion on latent inhibition. It certainly cannot be argued that the lack of effect is because of ineffectiveness of the lesions, because it has already been shown that central NA depletion produces significant deficits in certain types of appetitive discrimination, as well as other impairments. The negative result even assumes some con-

Table 3

Effects of 6-OHDA Lesions of DNAB on errors and Sessions to Criterion for Learning Following Latent Inhibition

\begin{tabular}{|c|c|c|c|c|c|c|c|c|}
\hline \multirow[b]{2}{*}{ Group (all $n=8$ ) } & \multicolumn{4}{|c|}{7 Days Postsurgery } & \multicolumn{4}{|c|}{ 14-21 Days Postsurgery } \\
\hline & Mean Errors & $( \pm$ SEM $)$ & Mean Sessions & $( \pm$ SEM $)$ & Mean Errors & $( \pm$ SEM $)$ & Mean Sessions & $( \pm$ SEM $)$ \\
\hline Sham preexposed & 616.5 & \pm 43.0 & 9.4 & \pm 1.3 & 458.8 & \pm 82.7 & 9.6 & \pm 0.9 \\
\hline Sham nonpreexposed & 514.5 & \pm 81.6 & 8.1 & \pm 1.1 & 344.1 & \pm 28.4 & 6.0 & \pm 0.5 \\
\hline DNAB preexposed & 671.9 & \pm 51.0 & 9.6 & \pm 0.7 & 528.5 & \pm 50.1 & 9.4 & \pm 0.7 \\
\hline DNAB nonpreexposed & 537.6 & \pm 58.4 & 6.0 & \pm 0.9 & 399.0 & \pm 53.4 & 6.6 & \pm 0.8 \\
\hline
\end{tabular}

Note-Unpublished data from Robbins et al. (1982). 
Table 4

Comparative Effects of Intracerebral 6-OHDA Lesions of DNAB, Neonatal 6-OHDA Lesions, and DSP-4 Pretreatment on Catecholamine Concentrations in Frontal Cortex, Hippocampus, and Striatum

\begin{tabular}{|c|c|c|c|c|c|c|}
\hline & \multirow[b]{2}{*}{$\mathrm{n}$} & \multicolumn{2}{|c|}{ Frontal Cortex } & \multirow{2}{*}{$\frac{\text { Hippocampus }}{\text { NA }}$} & \multicolumn{2}{|c|}{ Striatum } \\
\hline & & NA & DA & & NA & DA \\
\hline $\begin{array}{l}\text { 1. DNAB } \\
\text { Sham } \\
\% \text { depletion }\end{array}$ & $\begin{array}{l}18 \\
10\end{array}$ & $\begin{array}{c}0.038 \\
0.401 \\
91\end{array}$ & $\begin{array}{c}0.061 \\
0.053 \\
-\end{array}$ & $\begin{array}{c}0.051 \\
0.476 \\
89\end{array}$ & $\begin{array}{c}0.006 \\
0.036 \\
83\end{array}$ & $\begin{array}{c}9.66 \\
9.44 \\
-\end{array}$ \\
\hline $\begin{array}{l}\text { 2. Neonatal } \\
\text { 6-OHDA } \\
\text { Sham } \\
\% \text { depletion }\end{array}$ & $\begin{array}{l}14 \\
16\end{array}$ & $\begin{array}{c}0.098 \\
0.342 \\
71\end{array}$ & $\begin{array}{c}0.064 \\
0.059 \\
-\end{array}$ & - & $\frac{-}{-}$ & - \\
\hline $\begin{array}{l}\text { 3. DSP-4 } \\
\text { Control } \\
\% \text { depletion }\end{array}$ & $\begin{array}{l}8 \\
8\end{array}$ & $\begin{array}{c}0.031 \\
0.287 \\
89\end{array}$ & $\begin{array}{c}0.059 \\
0.048 \\
-\end{array}$ & $\begin{array}{c}0.023 \\
0.441 \\
95\end{array}$ & $\begin{array}{c}0.067 \\
0.108 \\
38\end{array}$ & $\begin{array}{c}9.56 \\
9.35 \\
- \\
\end{array}$ \\
\hline
\end{tabular}

Note-Values are expressed as median ng/mg tissue wet weight. DNAB lesions were made as described by Everitt et al. (1983). Neonatal rat pups received five ip injections of $100 \mathrm{mg} / \mathrm{kg}$ of 6-OHDA hydrobromide on Days $1,3,5,7$, and 9 after birth. DSP-4 treated rats received DSP4 (50 mg/kg ip) 2 weeks prior to testing. (Mohammed et al., 1984)

siderable importance, given that the same 6-OHDA DNAB lesion used by Lorden, Rickert, Dawson, and Pellymounter (1980) in tests of latent inhibition has also been reported by the same authors to attenuate blocking, another phenomenon of conditioning, which may involve a different type of attentional process from that of latent inhibition.

\section{Blocking}

In a blocking experiment, prior conditioning of a given conditioned stimulus (CS) to US evidently prevents con- ditioning accruing to an added stimulus compounded with the original CS (see Mackintosh, 1983). One interpretation of blocking is that it represents the ignoring of redundant (as contrasted with irrelevant) information (Mackintosh, 1983). In a study using a conditioned suppression paradigm, it has been reported that 6-OHDA lesions of the DNAB attenuate blocking (Lorden et al., 1980). Although this result seems quite clear-cut, it has to be pointed out that the experiment lacked the control groups necessary to show that blocking had occurred. Moreover, there appeared to be basic differences in prior conditioning to the CS in the DNAB group as measured by the conditioned suppression ratio, although these differences apparently were not significant.

Furthermore, the result has not been confirmed using other behavioral procedures. For example, in an experiment using a taste aversion paradigm and conditioning initially to a "noisy bottle," "unblocking" is observed rather than the more usual blocking - that is, the rats exhibit enhanced CTA to the added taste CS, indicating enhanced attention to the added stimulus during compound conditioning (Mohammed, Archer, \& Järbe, 1984). This unblocking effect was significantly attenuated rather than enhanced by DSP-4 pretreatment, thus representing an effect on attention opposite in direction to the attenuated blocking reported by Lorden et al. (1980).

Another example is the lack of effect of 6-OHDA lesions of the DNAB on an appetitive instrumental blocking procedure we have used. In this experiment, hungry rats were trained a few days after surgery to perform a conditional discrimination task in which the presence of a (centrally located) stimulus signaled that (for example) a left response was required for reinforcement, whereas

Latent inhibition

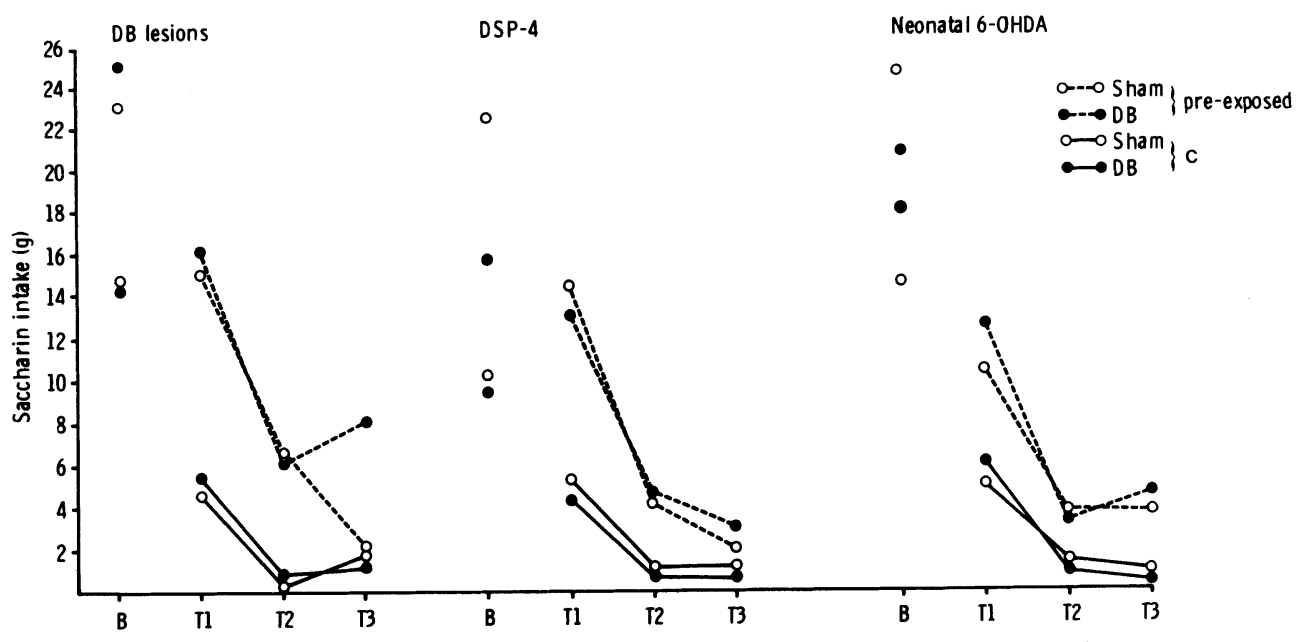

Figure 7. Comparative effects of 6-OHDA DNAB lesions, neonatal 6-OHDA lesions, and DSP-4, as different means of producing central NA depletion, upon saccharin intake in a conditioned taste aversion paradigm. Two groups of rats in each treatment condition received three 30-min periods of preexposure to the saccharin; the control (C) groups received no preexposure. Conditioning with $\mathrm{LiCl}$ injections occurred after the baseline (B) day and the first two test trials. The effects on retention were thus assessed over three test trials (T1-T3). Note that on the baseline day in each case, intake was significantly higher for all groups in the preexposed conditions compared with the corresponding unexposed groups. (Mohammed et al., 1984) 
the absence of a stimulus indicated that the alternative (right) response was correct. The stimuli used were light (L) (consisting of an array of three centrally located, $2.8 \mathrm{~V}$ bulbs) or a $7000-\mathrm{kHz}, 80 \mathrm{~dB}$ tone (T) delivered from a loudspeaker in the roof of the apparatus. There were two main conditions: Single, in which only one stimulus ( $\mathrm{L}$ or $\mathrm{T}$ ) was present, and Both, in which both stimuli were present $(\mathrm{L}+\mathrm{T})$ in a compound discriminative stimulus. Following surgery, rats were trained in one of the two conditions. There was a nonsignificant tendency for the rats with DNAB lesions to be worse at acquiring the task (see Table 5).

Blocking was then studied by introducing the alternative, novel stimulus in compound with the single stimulus to the rats in the Single condition. Hence, these groups now received $\mathrm{T}+\mathrm{L}$ presentations, with the added stimulus as an additional, redundant predictor of food reinforcement. The rats were given a number of reinforced presentations of the compound equivalent to the number of reinforced presentations of the same stimulus that the Both groups had received during training. Thus, the Single and Both groups experienced equivalent numbers of reinforced presentations of the added stimulus (whether $\mathrm{L}$ or $\mathrm{T}$ ). All groups received a degree of overtraining which ensured that baseline performance of the discrimination between the Single and Both conditions was at the same level. The original stimulus was then removed from the compound over five "unblocking" test sessions so that the conditioning that had accrued to the added stimulus in the Single condition could be directly compared with that in the Both condition, where it had been present throughout training. Overall performance was similar over the five sessions. The mean data, summarized in Figure 8, show that this procedure produced successful, although incomplete, blocking for both the light and tone conditions $[\mathrm{F}(1,36)=32.52, \mathrm{p}<.001]$. It is also clear that the light overshadowed the tone to some extent $[\mathrm{F}(1,36)=9.17$, $\mathrm{p}<.01]$. The DNAB lesion produced no significant effects on performance of any of the discriminations $[F(1,36)=1.36$, n.s. $]$, but most importantly for our present purposes, it did not alter blocking $[\mathrm{F}(1,36)=$

Table 5

Acquisition of Single and Both Discriminations in Blocking Experiments (Errors to Criterion)

\begin{tabular}{cccccc}
\hline & \multicolumn{2}{c}{ Light } & & \multicolumn{2}{c}{ Tone } \\
\cline { 2 - 3 } \cline { 5 - 6 } & Both & Single & & Both & Single \\
\hline Sham & 481 & 698 & & 546 & 1006 \\
$\mathrm{n}$ & 6 & 6 & 5 & 6 \\
DNAB & 623 & 798 & 733 & 1408 \\
$\mathrm{n}$ & 6 & 6 & 5 & 5 \\
\hline
\end{tabular}

Note-The acquisition criterion was defined as significant $(p<.05)$ discrimination for both the stimulus and no-stimulus portions of the discrimination within the same sessions. See text for further details. There was no significant effect of the DNAB lesion on acquisition $[F(1,37)=$ $2.81, n . s$.$] . The Both condition was acquired more easily than the Sin-$ gle condition $[F(1,37)=11.00, p<.01]$, and the Light conditions more easily than the Tone conditions $[F(1,37)=6.48, p<.05]$, but there were no significant interactions among any of the factors. The SED for the three-way interaction was 224.8 errors (Robbins \& Everitt, 1983).

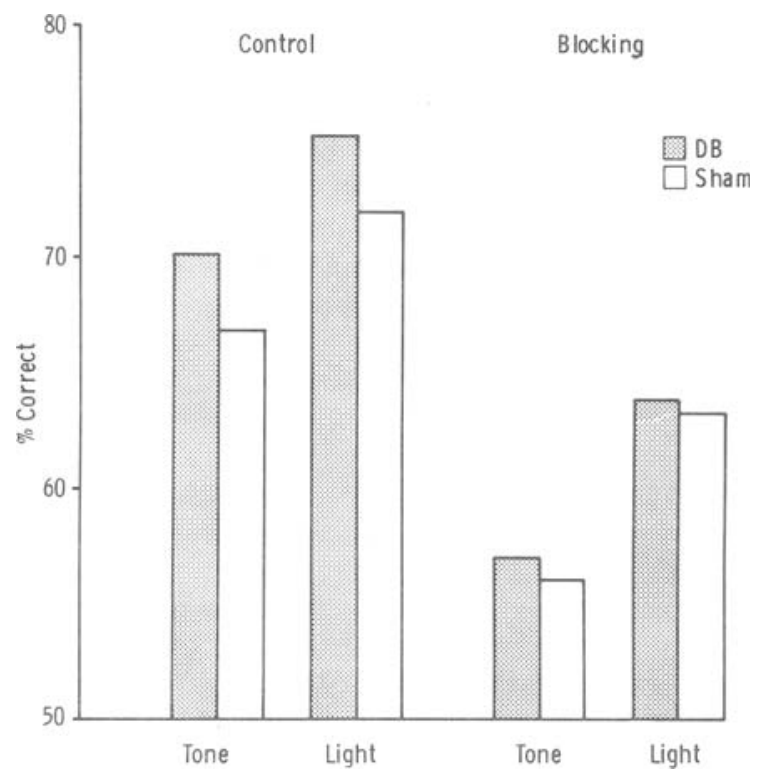

Figure 8. Failure of DNAB (DB) lesions to alter blocking in an instrumental appetitive procedure involving discrimination of tone + light (TL) compound stimuli from no stimulus. Groups received discriminative training with either $T$ or $L$ prior to training with the compound stimulus (TL). The histograms show the discrimination of the added element in the compound (either $T$ or $L$ ) when the pretrained element was omitted (averaged over five sessions). Note the significant effect of blocking on discrimination. (Robbins \& Everitt, 1983)

0.38 , n.s.]. Neurochemical assay data for a randomly selected sample of the rats used in this experiment are provided in Table 2 . As can be seen, the usual large depletions of cortical NA were obtained.

Evidently, Lorden et al.'s (1980) intriguing report of attenuated blocking following DNAB lesions needs further replication and analysis. Our failure to find significant effects could be due to the several differences between the paradigms used (for example, appetitive motivation was used in the present experiment, and aversive motivation involving a conditioned suppression procedure was used in the experiment by Lorden et al., 1980). Our negative results might also have been due to the fact that our blocking tests occurred at relatively long times after surgery (ranging from 7 to 12 weeks)-but it is by no means evident that the lesion is ineffective at these times. Lorden et al.'s finding of attenuated blocking, but unimpaired latent inhibition, is of considerable significance to certain theories of learning, which assume that blocking and latent inhibition are subserved by a common mechanism. However, as will be seen below, our own further examination of the effects of DNAB lesions on blocking has been hindered by the finding of baseline differences in conditioned suppression between DNABlesioned and sham control groups.

\section{Distraction and Surprise}

The selective attention hypothesis predicts that DNABlesioned rats will be unduly distractible as a result of fail- 
ing to screen out or habituate to irrelevant stimuli. The evidence on this is equivocal, to say the least. The most positive support has come from an experiment by Roberts, Price, and Fibiger (1976), who found a large increase in latency to traverse a T-maze by DNAB-lesioned rats when novel sandpaper and flashing lights were introduced to interfere with runway performance. This result is probably paralleled by analogous disruptions by electrolytic or chemical lesions of the DNAB of performance in the L-shaped runway (Anlezark, Crow, \& Greenway, 1973; Koob, Kelley, \& Mason, 1978; Owen et al., 1982), in brightness discriminations in mazes (Pisa \& Fibiger, $1983 \mathrm{~b}$ ), and in the open field in the context of a food neophobia test (Britton, Ksir, Thatcher-Britton, Young, \& Koob, 1984; and see results below).

In more confined apparatus, however, the introduction of a specific distracting stimulus such as a light or noise has been shown to produce contrasting and variable effects on performance measured in terms of suppression of licking or instrumental leverpressing (see Robbins \& Everitt, 1982, for a review). In our own temporal frequency discrimination procedure, introducing the alternative stimulus ( $\mathrm{L}$ or $\mathrm{T}$ ) as a novel distractor, synchronized with the relevant discriminative stimulus, produced significant but only slight disruption, which was equivalent in DNAB and sham-operated rats (Robbins et al., 1982). In rats overtrained on the task, the distracting stimuli had even less effect, and even (in the case of the added tone) improved discrimination in the sham controls, while having no effect in the DNAB group (Figure 9). In a five-choice serial visual localization task, Carli, Robbins, Evenden, and Everitt (1983) also found no differential disruptive effect in DNAB-lesioned and control rats of a loud white noise when introduced contemporaneously with the brief $(500-\mathrm{msec})$ visual events. Taken together, these results indicate no convincing deficit in the ability to ignore distracting events when these are presented at the same time as the relevant discriminanda. However, it is important that, when the same loud white noise was introduced in the intertrial interval (ITI), particularly immediately prior to the visual event, there were significant impairments in the accurate localization of the visual events in the DNAB group, but not in the sham control group (Carli et al., 1983). In a sense, this result parallels that of Roberts et al. (1976) - the disruption occurred when the animal was orienting and locomoting toward the relevant cues, rather than when the cues were actually presented. This distinction may parallel the different effects of lesions of the hippocampus or septum on distraction according to whether or not the animal is already engaged in a particular activity (see Gray, 1982, pp. 145-147).

A deficit in discrimination in the DNAB group performing the five-choice task was also observed if shorter than usual ITIs were used; this result occurred on two occasions, at both 37 and 64 days following surgery. A simi-

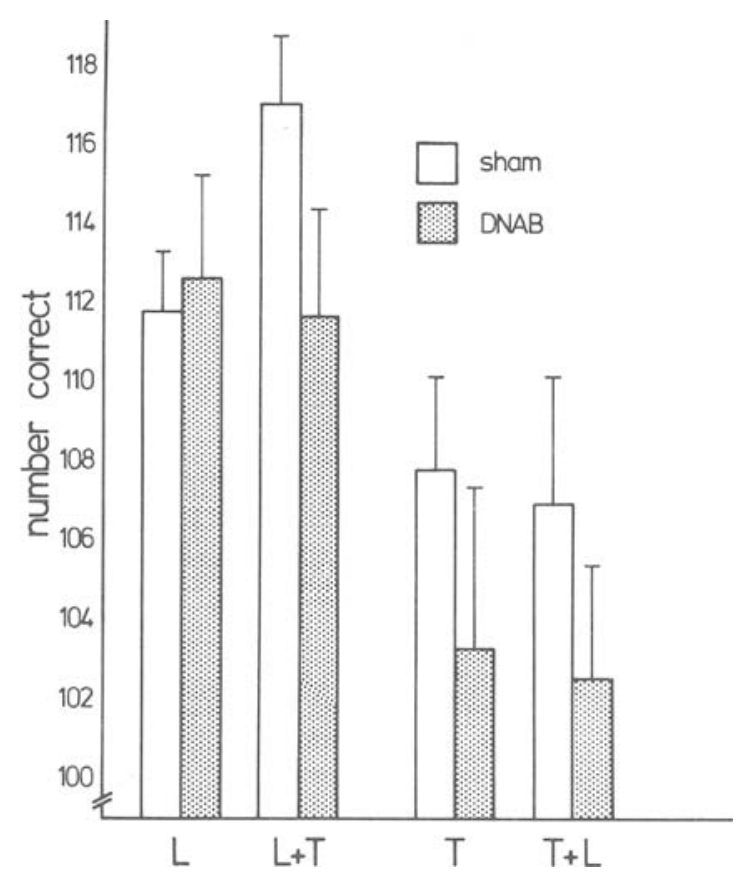

Figure 9. Effects of adding distracting tone (T) or light (L) to baseline discrimination (number correct out of 128) of the alternative modality in the temporal frequency discrimination. Note lack of disruption with added light for sham- and DNAB-lesioned rats (righthand histogram). Note small improvement in performance in sham group with the added tone, but no effect for the DNAB group. Data redrawn from Everitt et al. (1983).

lar result was found in the temporal frequency conditional discrimination (Everitt et al., 1983; see Figure 10).

In the latter experiment, we also found that the DNABlesioned rats were spending longer in the vicinity of the food tray; this could conceivably have interfered with effective orientation toward the discriminative cues (Carli et al., 1983). But if we define this as an "attentional" impairment, we run into semantic problems. In one sense, the food tray is as salient as the discriminative stimuli, and the deficit is a matter of switching attention too slowly (or enhanced focusing), rather than too readily, as is implied by the selective attention hypothesis.

The potential for distraction in DNAB-lesioned rats might be enhanced in conditions involving the short-term retention of information, such as the delayed response paradigm. We implemented a delayed-response version of the temporal frequency discrimination, in which a delay of $3 \mathrm{sec}$ was interposed between the offset of the discriminanda (the visual task was used) and the retraction of the two response levers into the chamber. Although this delay significantly and consistently impaired performance over many repeated sessions, there was no difference between the DNAB-lesioned and sham-operated control groups (Table 6). When a distractor (a brief illumination of the food magazine) was introduced on a proportion of the trials in the interval, performance was 


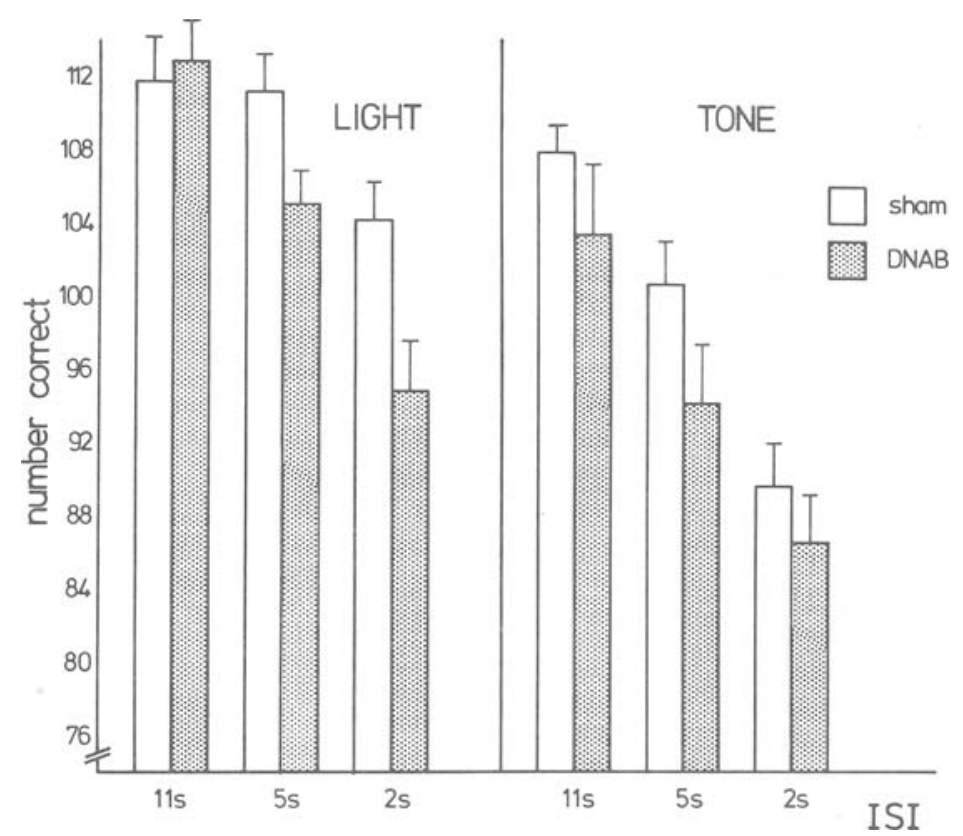

Figure 10. Effects of shortening the intertrial interval from 11 to 2 sec or the interstimulus interval (ISI) from the normal $11 \mathrm{sec}$ to 5 or $2 \mathrm{sec}$ on the number of correct choices (out of 128) in the temporal frequency discrimination. Note the separation of the sham- and DNAB-lesioned groups at shorter ISIs. Data redrawn from Everitt et al. (1983).

impaired still further, but again, to the same extent in both groups (see Table 6).

\section{ANXIETY HYPOTHESIS}

\section{Neophobia}

The apparently enhanced distraction observed in the open-field and runway situations would seem to be powerful evidence against the anxiety hypotheses of DNAB or LC function described by Gray (1982) and Redmond (1979). In the case of the open-field test, this effect apparently results in enhanced food neophobia, as the lesioned animals take significantly longer than controls to approach laboratory chow in the center of the field, even when severely deprived (Britton et al., 1984). This report of enhanced neophobia seems to agree with other reports based on amount of consumption of novel saccharin in the home cage, or consumption of other palatable food in a novel or familiar (home cage) environment (MartinIverson, Pisa, Chan, \& Fibiger, 1982; Mason, Roberts, \& Fibiger, 1978; Tombaugh, Pappas, et al., 1983).

However, some of our own recent work (Sahakian et al., 1983) indicates that the effects of DNAB lesions on neophobia are rather more complicated than at first seemed the case. A simple change was introduced into the procedure so that the rats were given a choice between a familiar food (chow) and a novel, palatable food (cheese) in two separate food bowls in a conventional novel open field with 10-min tests. Enhanced food neophobia in the DNAB group would presumably be reflected by enhanced rejection of the cheese in favor of the chow. In fact, precisely the opposite was found-the DNAB group initially

Table 6

DNAB Lesions and Delayed Discrimination

\begin{tabular}{lccccc}
\hline & $\begin{array}{c}\text { Baseline } \\
\text { (Light) }\end{array}$ & $\begin{array}{c}\text { Delayed Response* } \\
\text { (First Session) }\end{array}$ & $\begin{array}{c}\text { Delayed Response* } \\
\text { (Last Session) }\end{array}$ & $\begin{array}{c}\text { Delayed Response + } \\
\text { Distraction } \\
\text { (First Session) }\end{array}$ & $\begin{array}{c}\text { Delayed Response + } \\
\text { Distraction } \\
\text { (Last Session) }\end{array}$ \\
\hline Sham & 107.1 & 87.2 & 90.4 & 72.6 & 74.4 \\
$(\mathrm{n}=9)$ & \pm 1.3 & \pm 6.3 & \pm 7.0 & \pm 2.2 & \pm 12.2 \\
DNAB & 103.9 & 80.0 & 86.6 & 68.2 & 66.3 \\
$(\mathrm{n}=7)$ & \pm 12.0 & \pm 5.6 & \pm 5.1 & \pm 1.7 & \pm 2.8 \\
\hline
\end{tabular}

Note-All DNAB versus sham comparisons: $p>.05$. Mean + SE of number of correct responses (maximum $=128$ ). The visual version of the conditional discrimination of temporal frequency as described by Everitt et al. (1983) was used. Following attainment of the $85 \%$ criterion and subsequent stabilization on the basic discrimination with no delay (Baseline), rats received a 3-sec delay between stimulus presentation and availability of the response manipulanda. About 10 sessions were given under these conditions, prior to the introduction of a distracting condition in which the magazine light was illuminated during the delay. About 5 sessions were run under this condition. The experiments occurred about 2-3 months following surgery. Unpublished data of Robbins et al. (1983). *3 sec. 
chose to eat the cheese, rather than the chow. The result has since been replicated, but in experiments in which food deprivation level and handling experience were manipulated, and rats were tested sooner after surgery (14 days; Cole, Robbins, Jones, Dooley, \& Everitt, 1985). More measures of performance were also utilized than were possible in the experiment by Sahakian et al.

Some of the data are shown in Table 7 and Figures 11 and 12. As can be seen from Table 7, the DNAB group tended initially to choose cheese rather than chow, but also tended not to choose either type of food. In other words, the DNAB-lesioned rats were often less inclined to eat in the open field, but if they did eat, they chose initially to consume the novel food.

The results for latency to eat (Figure 11) reflected those for the initial choice. Whereas the sham rats took longer to begin eating the novel cheese than the familiar chow, the DNAB-lesioned rats did not show any differences between the two foods [lesion $\times$ food interaction, $F(1,64)$ $=6.923, \mathrm{p}<.01]$. This pattern is particularly surprising in view of the quite dramatic differences shown by the DNAB-lesioned groups in latency to contact (but not eat) the food (whether cheese or chow). Although they were somewhat quicker to contact the foods at the lower level of deprivation, Figure 12 shows that the DNABlesioned rats exhibited a highly significant retardation of contacting the foods at $48 \mathrm{~h}$ deprivation [lesion $\times$ deprivation interaction, $F(1,64)=6.121, \mathrm{p}<.01]$. Thus, there is a quite remarkable dissociation. First, it seems likely that the DNAB rats are much more likely to begin eating following their initial contact with the food, even though (at $48 \mathrm{~h}$ ) the contact latency is much slower. Second, if and when the DNAB rats do eat, they have a significant tendency to choose the novel, palatable cheese rather than the more familiar, less palatable laboratory chow. To say that DNAB-lesioned rats show globally either an enhanced or diminished neophobia or response to novelty is clearly inappropriate here, because both interpretations could be made from these data, depending on which variable is considered.

It seems possible that there are two effects of the DNAB lesions: (1) a reduced tendency to eat in a novel, illuminated environment-perhaps because of a reluctance to visit the central squares of the open field where the food

Table 7

Effects of DNAB Lesions on Food Neophobia in a Choice Paradigm: Initial Choice

\begin{tabular}{lcccc}
\hline & Novel Cheese & Familiar Chow & Neither & Total \\
\hline DNAB & 12 & 12 & 12 & 36 \\
Sham & 6 & 23 & 7 & 36 \\
Total & 18 & 35 & 19 & 72 \\
\hline
\end{tabular}

Note $-\chi^{2}(2)=6.88, p<.05$. The data shown indicate the incidence of initial choice (defined as $\geq 3$ sec of eating) for novel cheese, familiar chow, or neither. Data are collapsed across two food deprivation conditions $(24$ and $48 h)$ and handled and unhandled groups. The data were collected between 14 and 21 days postsurgery (Cole et al., 1985).

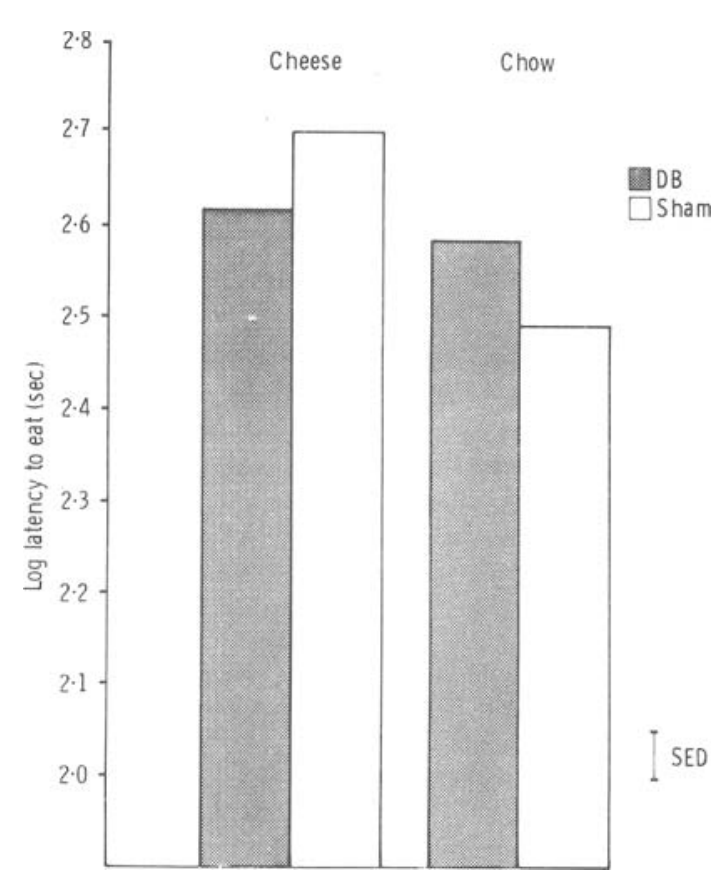

Figure 11. Log latency (in seconds) to begin eating novel cheese or familiar chow in an open field by DNAB-lesioned or shamoperated rats. SED = 1 standard error of the difference between the means of the lesion and sham groups. (Cole et al., 1985)

bowls are located; and (2) a tendency to choose the novel food, if the animal eats at all.

Crudely speaking, it seems as though, whereas the nonspecific suppression of feeding by a novel environment (environmental neophobia) is enhanced, the tendency to avoid novel food (at least in novel situations) is reduced by DNAB lesions (i.e., quite the opposite of what might be expected in terms of food neophobia). It is obviously worth reconsidering these data in light of the published literature. The enhanced environmental effects would seem to correspond to the reduced tendency to eat (or approach) food in a novel environment reported by Britton et al. (1984), and possibly also to the generally enhanced latency to eat in all environments reported by MartinIverson et al. (1982). Reduced saccharin consumption in the home cage may not fit with this interpretation, but this result may not necessarily reflect neophobia so much as reactivity to the sensory properties of saccharin solutions, and in any case, we have not reliably replicated this result following either DNAB lesions (Dunn \& Everitt, 1985) or DSP-4 treatment (Archer, Cotic, \& Järbe, 1982). In a broader context, the results may also fit with Roberts et al.'s (1976) finding of distractibility in DNAB-lesioned rats to novel stimuli in a T-maze, and with the enhanced reactivity to the food runway seen in unhandled DNABlesioned rats by Owen et al. (1982). In both cases, there was an enhanced latency to negotiate the maze and reach the food. In our particular circumstances, it was quite difficult to pinpoint a variable or set of variables that reli- 


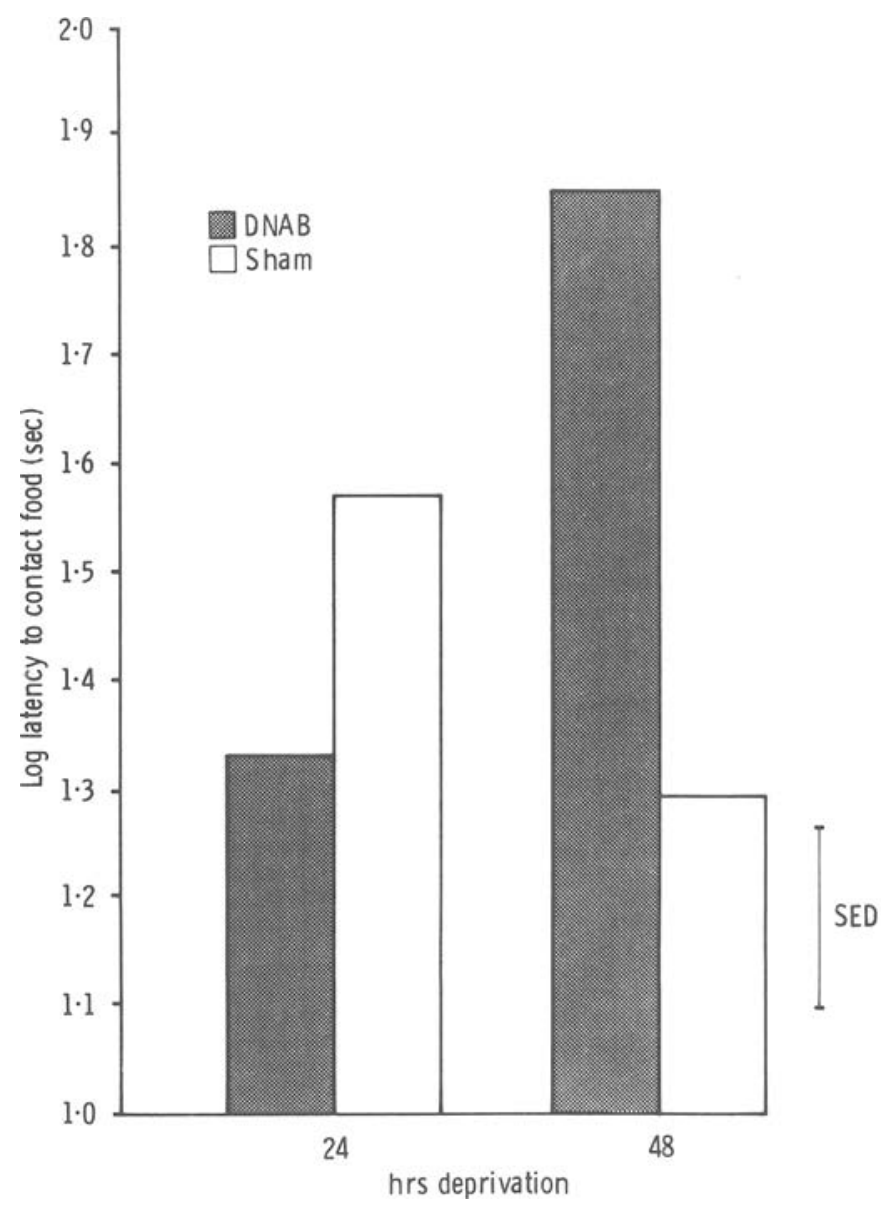

Figure 12. Log latency (in seconds) to contact food (novel or familiar) in 10min open-field test in sham- or DNAB-lesioned groups at different levels of food deprivation. SED = 1 standard error of the difference between the means of the lesion and sham groups. (Cole et al., 1985)

ably enhanced the effect in DNAB-lesioned rats, because, for example, there was no significant handling $\times$ lesion interaction term for the latency-to-contact measure. On the other hand, the effect was seen only when the animals were quite severely deprived $(48 \mathrm{~h})$, rather than at lower levels of deprivation, and in a separate experiment, Cole, Robbins, Jones, Dooley, and Everitt (1985) found that enhanced latency to contact the food was shown specifically in novel environments. Thus, the DNAB-lesioned rat is made more sensitive to the suppressant effect of the environment on food intake if it is either severely deprived or tested in a novel situation. Therefore, it is possible that both exteroceptive and interoceptive cues contribute to this form of hyperreactivity in the DNAB-lesioned rat.

A potential problem with the procedure used by Sahakian et al. (1983) for testing food neophobia lies in the fact that the novelty of the cheese is confounded with its high degree of palatability, relative to chow. In addition, the choice between novel and familiar food was allowed only in a brightly illuminated, novel environment, so we cannot be sure of its contributions to the neophobia effects.
Thus, in recent experiments, Cole et al. (1985) controlled these factors by preexposing rats either to the open field or to one of two equivalently palatable foods (cheese or biscuit). Some of the results for DNAB-lesioned rats or sham-operated controls 3 months following surgery are shown in Table 8. As can be seen, the sham-operated rats exhibited a characteristically different pattern of initial choices between the familiar and novel environments, preferring novel food in the former and familiar food in the latter. However, the DNAB-lesioned rats failed to discriminate between the novel and the familiar aspects of the food, and as a group chose randomly in both the familiar and novel conditions. This was not simply because the DNAB-lesioned rats could not discriminate between the two foods, because they showed a significant initial preference (not seen in the sham controls) for the biscuit. Thus, unlike the sham-operated rats, which were mainly choosing between the foods on the basis of their novelty, the DNAB-lesioned rats were attending to a different dimension, in both novel and familiar test environments. There were no significant differences in other 
Table 8

DNAB Lesions and Neophobia

\begin{tabular}{lrccr}
\hline & Familiar Food & Novel Food & Neither & Total \\
\hline \multirow{5}{*}{ Sham } & \multicolumn{3}{c}{ Familiar Environment } \\
DNAB & 1 & 5 & 1 & 7 \\
& 3 & 4 & 0 & 7 \\
Sham & & Novel Environment & & \\
DNAB & 7 & 0 & 0 & 7 \\
Total & 3 & 3 & 1 & 7 \\
& 14 & 12 & 2 & 28 \\
\hline
\end{tabular}

Note-Incidence of rats choosing familiar food, novel food, or neither in a 10-min open-field test. Contingency table analysis shows a significant lesion $\times$ test environment interaction $\left[\chi^{2}(2)=10.66, p<.01\right]$. Unpublished data of Cole et al. (1985).

measures taken in this situation, for example, in latency to contact or eat food and in duration of feeding. This is particularly interesting because in a separate group of rats tested much sooner ( 2 weeks following surgery), such differences were, in fact, present, and replicated those seen in the experiments described using cheese and chow. Particularly important was the replication of the finding of enhanced latency to make initial contact with the foods.

In summary, it would appear that: (1) the measure of initial choice produces effects which are qualitatively similar between 2 weeks and 3 months following surgery; (2) the measures concerning latency and duration were sensitive to the effect of the lesion at 2 weeks, but not 3 months, after surgery; and (3) the effects on latency to contact food and to eat and on duration of feeding at 2 weeks depended on the novelty of the test environment and the deprivation level of the animal, with the largest effects manifested in quite severely deprived rats in novel environments.

The theoretical implications of these findings are intriguing, but pose a number of problems. First, it cannot be said that the DNAB lesion alters the response to novel stimulation globally in one way or another. Thus, the lesion seems either to enhance the effects of response to novelty (environmental neophobia) or to diminish them (food neophobia). The main question is whether this seeming paradox is the result of the lesion's disrupting a unitary behavioral or physiological process, which leads to the apparently contrasting behavioral effects, or if, for example, different behavioral processes organized within the different terminal regions of the coeruleocortical systems are involved. It is noteworthy that a recent paper by Borsini and Rolls (1984) reported that NA depletion within the amygdala induced by infusions of 6-OHDA there increased the latency to eat, but did not affect choice of familiar or novel foods (as measured by relative time spent feeding). On the other hand, infusions of NA, at low doses, did increase the tendency to spend more time eating familiar foods, as we would have expected on the basis of our results. At a higher dose, the latency to eat was reduced. These intriguing, but not entirely complementary, effects of NA depletion and NA infusions within the amygdala deserve further attention. It would also be of interest to measure initial choice of food, as we have done, to obtain a more comparable set of data. The environmental neophobia, on the other hand, may have a different neuroanatomical substrate. It is even possible, for example, that it results from hypothalamic NA depletion, as extinction of aversively conditioned behavior appears to depend on damage to the VNAB rather than the DNAB (see below), and the enhanced environmental neophobia could reflect retarded habituation to phobic visual stimuli (cf. Pisa \& Fibiger, 1983b).

Our results with the neophobia paradigm are more consistent, in our experience, than other reported results of DNAB lesions on measures of reaction to novelty and exploration. For example, Pisa and Fibiger (1983a) reported that DNAB lesions reduced spontaneous alternation. In ancillary studies we have performed, using the same rats as in the neophobia experiment reported in Table 7, there was also an attenuation of the normal spontaneous alternation tendency in a $\mathrm{T}$-maze (sham, $37 / 48=77 \%$; DNAB, $28 / 44=59 \%$ ), although this is not statistically significant. We have also on occasion observed reductions in the tendency of DNAB-lesioned rats to rear in relatively novel situations, as reported also by Gray (1982) and Britton et al. (1984); but, again, we have not consistently observed this result across different groups of animals.

The dissociation of effects seen for environmental neophobia and food neophobia does perhaps parallel the pattern of effects reported by Mason et al. (1978), who showed that the DNAB lesion reduced the initial response to a novel stimulus, whereas it increased the duration of time subsequently spent exploring the stimulus. However, it is difficult to see how these patterns of results can easily be related to the attentional hypothesis.

The anxiety hypothesis fares little better, because it has to predict a reduced response to novel (threatening) situations. At least one form of the anxiety hypothesis suggests that the effects of DNAB lesions should be similar to those of anxiolytic drugs, such as the benzodiazepines chlordiazepoxide and diazepam. However, this is not the case. Cole et al. (1985) have found that chlordiazepoxide, over a wide dose-response range $(7.5-15.0 \mathrm{mg} / \mathrm{kg}$ ), reduced the latency to eat at doses which did not alter the latency to contact the food. Moreover, there was no effect on initial choice of food at any dose. This failure to reproduce the pattern of results seen with DNAB lesions presents clear problems for the anxiety hypothesis of DNAB function.

\section{Conditioned Emotional Response (CER)}

The effect of DNAB lesions on aversively motivated behavior is clearly a vital question for the anxiety hypothesis. If DNAB lesions were to mimic the effects of anxiolytic drugs, as the anxiety hypothesis of Gray implies, then such lesions might be expected to increase punished responding and reduce on-the-baseline conditioned suppression, but to have no effect on off-the-baseline conditioned suppression (Gray, 1982). 
Much of the earlier literature failed to find effects of DNAB lesions on acquisition of conditioned suppression (Gray, 1982), but recent experiments by Tsaltas, Gray, and Fillenz (1984) reported that there was an attenuation of on-the-baseline conditioned suppression, which emerged during the later stages of acquisition of an onthe-baseline procedure. One possible reason for the different results may have been the use of different levels of footshock, which were high ( $\geq 1.0 \mathrm{~mA}$ ) in earlier work, but low $(0.2 \mathrm{~mA})$ in the experiments of Tsaltas et al.

The positive results reported in the latter work were interpreted against the view that the DNAB was involved in learning because they did not involve early acquisition, and in favor of the anxiety hypothesis because they appeared to involve the ultimate level of performance of the CER. However, it might be argued that the effect was ambiguous, because it is difficult to determine when the acquisition phase of the CER ends. Another possible complication is that the rats were trained on the appetitive component of the CER procedure only after the lesion, meaning that the CER studies were actually carried out several weeks following surgery, thus possibly reducing the effects of the lesion.

In our experiments (Cole \& Robbins, 1985), the rats were trained prior to surgery, and a higher level of footshock $(0.5 \mathrm{~mA})$ was used than that used in the experiments of Tsaltas et al. (1984). Initially, three groups were studied: DNAB-lesioned, sham control, and unoperated control. Following training under a variable-interval (VI) schedule of food reinforcement, the rats received five pairings of a 30-sec light CS preceding a 0.5 -sec footshock, over 7 consecutive days. The rate of responding during the CS and in an equivalent, immediately preceding, period was separaiely measured, thus allowing the computation of a conditioned suppression ratio. Results for this measure averaged over the 7 days are shown in Figure 13. There was a significant main effect of groups, reflecting significantly reduced conditioned suppression in the DNAB group relative to the two control groups. Thus, it appeared that the acquisition of conditioned suppression was impaired by DNAB lesions. There were significant concomitant changes in CS rate and pre-CS rate following DNAB lesions (a detailed account of which is beyond our present scope). However, a similar effect on conditioned suppression was found 2 months following surgery in a different group of rats, but without significant concomitant changes in CS or pre-CS rate (Cole \& Robbins, 1985). This shows that such significant changes in response rate are not a necessary prerequisite for the elevated conditioned suppression ratios. It also demonstrates, as in the neophobia experiment, that relatively long-lasting effects of DNAB lesions can be obtained (although, in this case, quantitatively smaller ones) which are consistent over a lengthy period (2-3 months) following surgery.

In order to test whether these effects might be due in part to hypothalamic NA depletion, a parallel experiment

\section{On the baseline conditioned suppression acquisition}

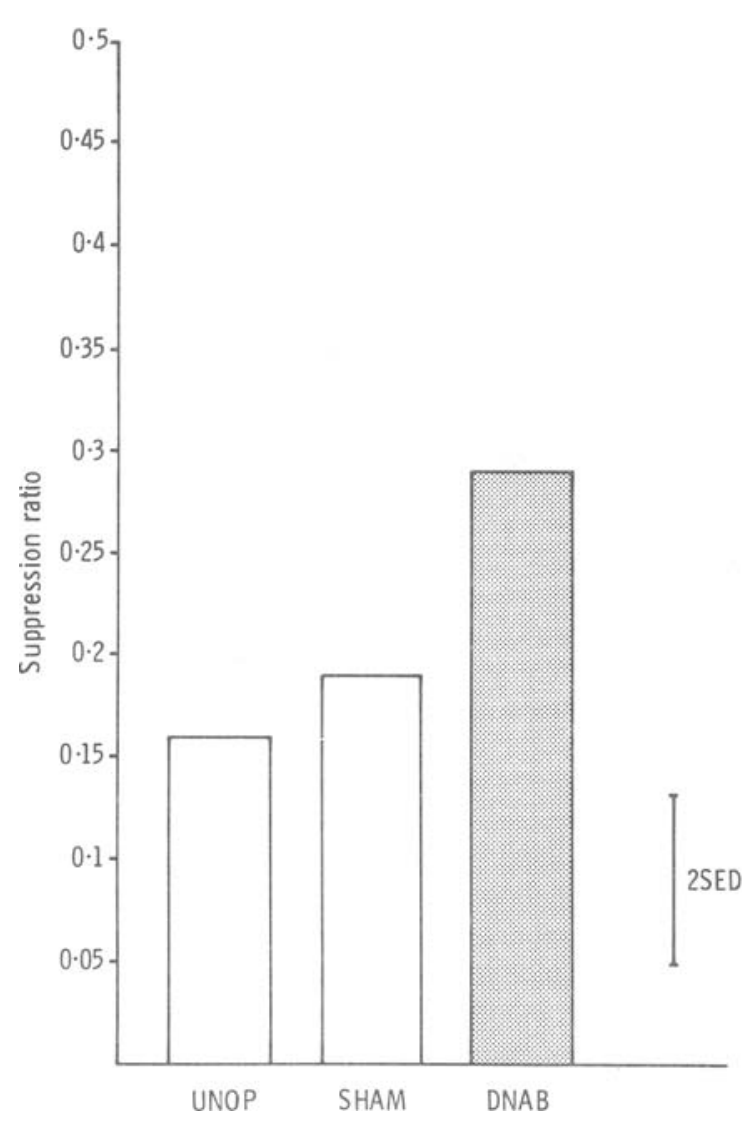

Figure 13. Effects of DNAB lesions on acquisition of on-thebaseline conditioned suppression, averaged over seven acquisition sessions. UNOP = unoperated controls; SHAM = sham-operated controls. Higher scores indicate impaired acquisition. 2 SED = 2 standard errors of the difference between the means of the three groups. (Cole \& Robbins, 1985)

was run with VNAB lesions, as above, but there were no effects of this treatment, emphasizing the likely involvement of the cortical depletion instead (Cole \& Robbins, 1985).

The effect of DNAB lesions on the performance of previously acquired on-the-baseline conditioned suppression was assessed by operating upon the intact rats used as controls in the acquisition experiment. As can be seen in Figure 14, there was, remarkably, no effect of DNAB lesions. Therefore, the effect of cortical NA depletion once again was restricted to the acquisition stage of the experiment. This result also stands in contrast to the effects of anxiolytic drugs, which attenuate conditioned suppression when previously established by prior training (Gray, 1982).

The on-the-baseline conditioned procedure confounds the measurement of pure Pavlovian conditioning with the adventitious punishment of instrumental appetitive 
On the baseline conditioned suppression performance

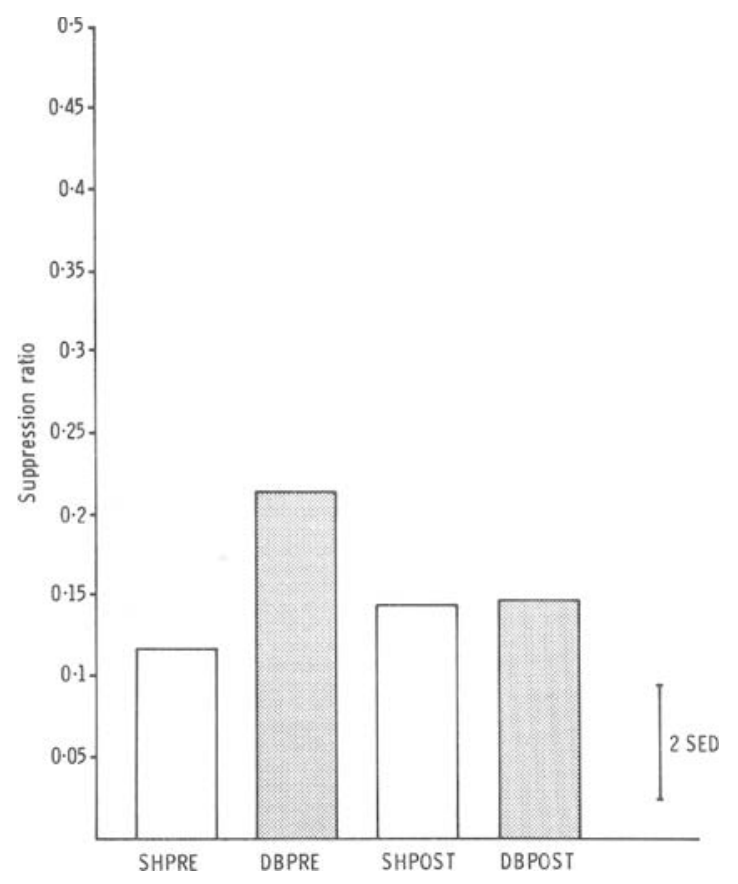

Figure 14. Effects of DNAB lesions (DB) or sham operations (SH) on performance of on-the-baseline conditioned suppression when the rats were operated on either prior to (DB PRE, SH PRE) or following (DB POST, SH POST) acquisition sessions. 2 SED $=2$ standard errors of the difference between the means of the three groups. The DNAB lesion impaired performance (i.e., increased the suppression ratio) only when made prior to training. (Cole \& Robbins, 1985)

responses. A less confounded measure of Pavlovian conditioning can be obtained with an off-the-baseline procedure, in which conditioning is carried out in the same environment, but at a time when the rat is not permitted to respond under the appetitive schedule. Conditioning is subsequently measured by presenting the aversive CS when the rat is responding for food, in the absence of the shock. Strictly speaking, effects on learning, as opposed to extinction, can be inferred only from the first of such presentations. A recent experiment (Cole \& Robbins, 1985) has confirmed that DNAB lesions impair off-thebaseline classical conditioning, as measured in each of the first three trials of the test session (see Figure 15).

Extinction of both on-the-baseline and off-the-baseline conditioned aversive associations was measured, in view of reports of the retardation of extinction of such responses following DNAB lesions (for a review see Mason, 1983). There was a transient effect of DNAB lesions in this direction for the on-the-baseline experiment and a similar tendency for the off-the-baseline study. These results would seem to argue against the anxiety hypothesis, because the aversive impact of the conditioned stimuli appeared to be prolonged. However, it is quite likely that these small effects of extinction resulted not from damage to the corti- cal NA projection, but from hypothalamic NA depletion, probably because of incidental damage to the VNAB. This conclusion is based on two facts. First, although the acquisition of on-the-baseline conditioned suppression was unaffected by VNAB lesions, its extinction was retarded over several test sessions, to a much greater extent than for the DNAB lesions (Cole \& Robbins, 1985). Second, in an extensive series of experiments on CTA, Dunn and Everitt (1985) have found that VNAB lesions have an exactly parallel effect, not altering acquisition of CTA, but greatly prolonging its extinction (see Figure 16). Therefore, (1) DNAB and VNAB lesions produce dissociable effects of the acquisition and extinction of aversive conditioning; and (2) the effects of DNAB lesions are mainly restricted to the acquisition of aversive conditioning, rather than its maintenance, unlike the effects of anxiolytic drugs; this contradicts the anxiety hypothesis of DNAB function, at least as formulated by Gray (1982).

\section{DOES THE LC HAVE A UNITARY FUNCTION?}

From the work described so far, it is evident that lesions of the DNAB have somewhat diverse effects, which cannot all be easily assimilated into either an "attentional" or an "anxiety" account of the functions of the LC. But the fact remains that these sometimes bewildering patterns of effects could result from the coeruleocortical system's normal activity under a particular set of circumstances. Single-unit recording from the LC certainly encourages this view. These cells are active during waking, rather than during sleep (Aston-Jones \& Bloom, 1981a). Perhaps even more significantly, they respond to a variety of different sensory events from several modalities (Foote, Aston-Jones, \& Bloom, 1980). It could well be asked to what special aspects of the stimuli the cells respond. One important study, by Watabe, Nakai, and Kasamatsu (1982), has addressed this issue. Watabe et al. found evidence of firing, not to specific features of visual stimui, such as their orientation, but rather, to grosser aspects of the stimuli, such as their overall intensity. This indicates that the LC NA cells are not supplied with detailed spatiotemporal information about the external environment. According to Aston-Jones and Bloom (1981b), these cells also respond to novel aspects of the stimuli, so they are not merely responding to stimulus intensity, but more probably to stimulus salience. Manipulation of such salience by various forms of conditioning would add enormously to our understanding of LC functions.

In addition to this evidence that the $\mathrm{LC}$ is active in rather general circumstances is the supporting neurochemical data from a number of sources suggesting that turnover is elevated in the coeruleocortical projection in response to a variety of stressors or stressful conditions (see Robbins \& Everitt, 1982).

If it can for the moment be assumed that the LC is indeed activated under conditions of stress, or in response to stimuli of significance, it is worth considering not the 
(OFF-THE-BASELINE)

Suppression Ratios
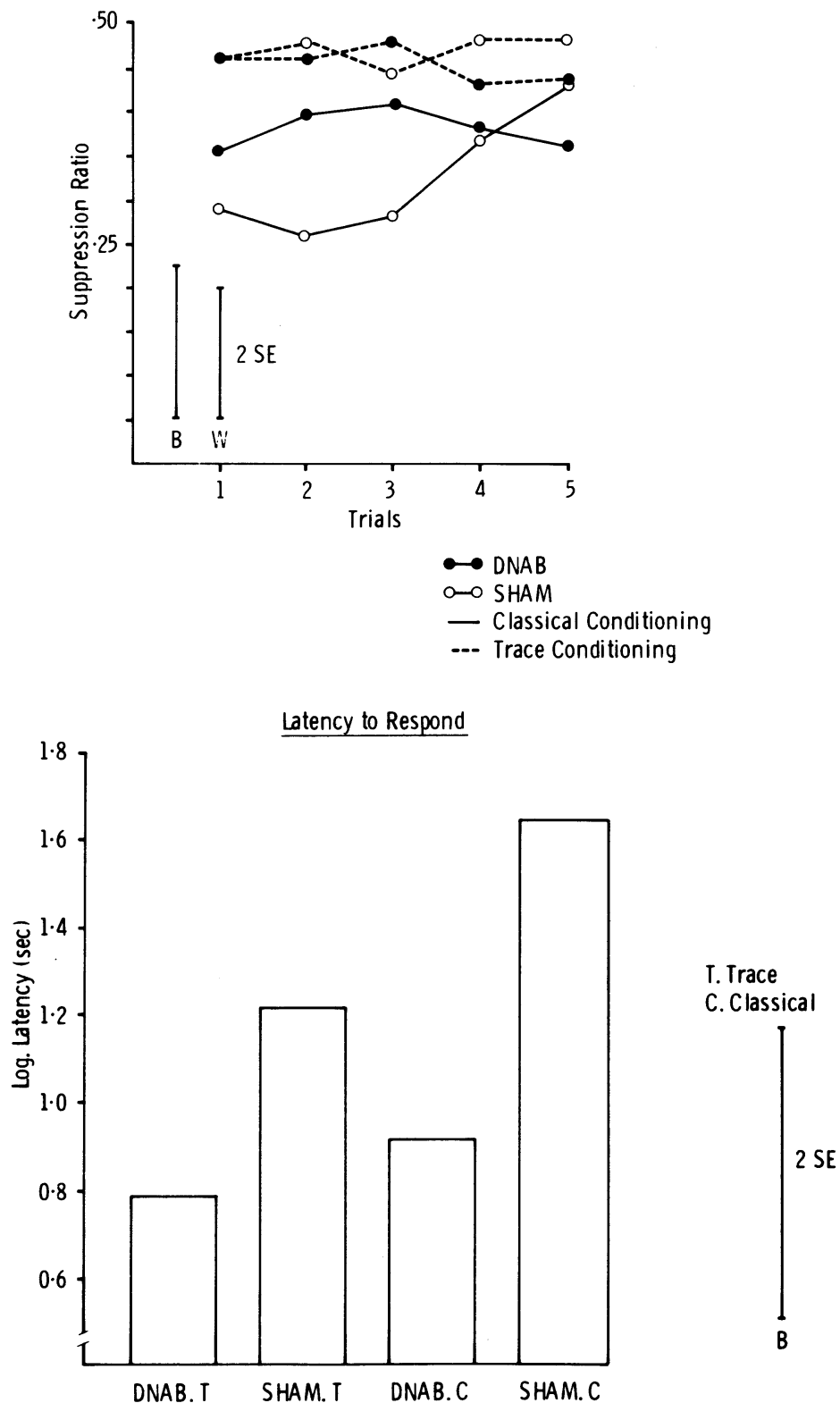

Figure 15. Effects of DNAB lesions or sham operations on acquisition of offthe-baseline conditioned suppression, for classically conditioned and traceconditioned groups (30-sec CS, 30-sec delay, 0.5-sec UCS). Top panel: The DNABlesioned rats in the classically conditioned group showed significant impairments (higher suppression ratios) on Trials 1, 2, and 3, but not on Trials 4 and 5. Bottom panel: Effect of DNAB lesions or sham operations on latency to make the first response (index of contextual conditioning); the DNAB-lesioned rats were significantly quicker to respond. $2 \mathrm{SE}=2$ standard errors for between (B) or within (W) rat variation. (Cole \& Robbins, 1984b, 1985) 


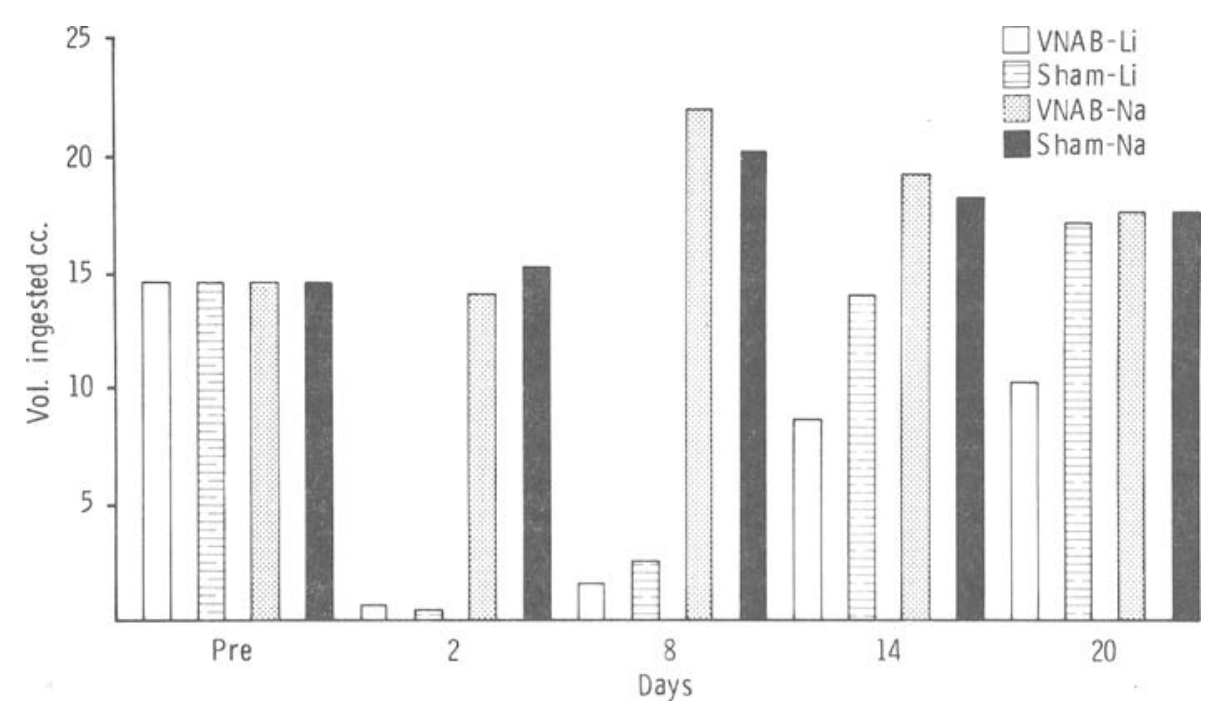

Figure 16. Effects of VNAB lesions or sham operations on conditioned taste aversion following baseline (Pre) to saccharin solution by $0.15 \mathrm{M}$ lithium chloride (Li) or control (Na). Note retarded extinction in VNAB group. (Dunn \& Everitt, 1985)

unitary function of coeruleal neurons at the cell body level, but the differing consequences of such activation at the widely disparate cortical terminal regions to which they project. From our previous discussion of the effects of microiontophoretically applied NA, it is clear that there could well be a common action of the coeruleal projections in terms of enhanced $\mathrm{S} / \mathrm{N}$ ratio of evoked firing in the various terminal regions. As has been hinted in previous sections, the major factor determining the at times bewildering pattern of effects would then be the nature of the processing occurring in the various regions of innervation. The LC may well be involved in behavioral inhibition (see Gray, 1982), selective attention (Mason \& Iversen, 1979), and even learning (Crow, 1968) because of its activation in stressful or other special circumstances.

The above argument is a summary of an earlier article (Robbins, 1984), which suggested that the LC preserves selective attention during both times of stress and times of underarousal. Thus, in the absence of malfunction of the coeruleocortical projection, the animal is less able to respond in a discriminating way to its environment. According to this hypothesis, a lesion of the DNAB does not, for example, reduce anxiety or stress, but merely alters their effects (in a way which may well ultimately further elevate the stress). The activation of the coeruleocortical NA projection is seen as a part of a coordinated response to stress which serves to protect and enhance the organism's cognitive capabilities at a time when its body is also preparing itself to meet the metabolic and physiological challenges of the situation. A related hypothesis has been advanced by Amaral and Sinnamon (1977). There are several lines of evidence arising from our own work that support this position.

It is evident from the work we have reviewed that the DNAB lesion deficit often becomes apparent only under difficult or stressful conditions, particularly during acqui- sition. Thus, DNAB lesions impair the acquisition of conditional appetitive discriminations, CER, and the eating response to tail-pinch stimulation (which might have a "coping" function; see Sahakian et al., 1983). In contrast, once established, none of these forms of conditioning is affected by DNAB lesions. This pattern of results fits with the general assumption that acquisition is more likely to involve complex processing by cortical and limbic mechanisms than established performance and thus implicates the coeruleocortical NA projection.

Two additional lines of evidence from our own work support this hypothesis. One of these is the previously published data on the effects of DNAB lesions on a five-choice serial-reaction visual-localization task (Carli et al., 1983). In these experiments it was found that DNAB lesions failed to alter accurate visual localization in normal conditions, but led to an impairment of discrimination when bursts of loud white noise were interpolated in the ITI (although not contemporaneously with the visual discriminanda). For both the sham-operated and DNAB groups, the white noise had an equivalent behaviorally activating effect on responding-seen as an enhanced incidence of premature responses (prior to the occurrence of the visual targets) and faster reaction times, at least when the response was incorrect. And yet, despite this evident disruption of behavior, the sham-operated rats were able to accurately discriminate the visual targets when they allowed themselves the opportunity to do so. By contrast, the DNAB-lesioned group, although showing equivalent degrees of impulsive responding (behavioral disinhibition), exhibited impairments in discrimination compared with the no-distractor conditions (see Carli et al., 1983).

These results are of considerable theoretical significance because they are consistent with the suggestion that under activating conditions (defined behaviorally by quicker and more impulsive behavior), the DNAB-lesioned rats 
are less able to make accurate choices-presumably because their capacity to discriminate signal from noise has been impaired. The results further suggest that the effects of DNAB lesions may become apparent during stress, particularly when it leads to increases in motor output (defined here as activation).

The behavioral effects of white noise were strikingly similar to those of systemically administered damphetamine, which also produces changes in reaction time and, more particularly, increases in premature responses, but fails to alter discrimination, even at high doses in normal animals (see Robbins \& Sahakian, 1983). A prediction of the hypothesis was that d-amphetamine would produce similar effects on premature responses, but would impair discrimination in DNAB-lesioned rats. This result was found by Cole and Robbins (1984a) for low $(0.2-0.6 \mathrm{mg} / \mathrm{kg})$ doses of d-amphetamine administered ip, and also for a range of doses (10-30 $\mu \mathrm{g})$ administered bilaterally directly into the nucleus accumbens, which, of course, receives a strong dopamine (DA) projection from the ventral tegmental area. More direct evidence for a dopaminergic mediation of the effects of central amphetamine was found from the antagonism of its effects by the neuroleptic $\alpha$-flupenthixol (Cole $\&$ Robbins, 1984a). Thus, it appeared that dopaminergic activation produced by amphetamine led to impairments in discrimination in DNAB-lesioned rats that were not seen in intact animals.

These results are important for two reasons: first, they lend support to the tentative hypothesis advanced above that DNAB contributes to a "supervisory" type of mechanism which protects the organism from making errors of either stimulus or response selection (Robbins, 1984); second, they cast some further light on the important topic of NA-DA interactions (Antelman \& Caggiula, 1977).

The other aspect of the hypothesis outlined by Robbins (1984)-that the coeruleocortical NA system contributes to a mechanism that compensates for reduced arousal, as well as the overarousal and activation produced by stress-has not been tested thoroughly as yet. Evidence supporting this part of the hypothesis derives from the report that DNAB lesions in combination with adrenalectomy impair the acquisition of active avoidance, whereas these treatments have little effect by themselves (Ögren \& Fuxe, 1974). Thus, according to the model, activity in a neural mechanism modulated by the coeruleocortical pathway may normally compensate for the potentially disruptive behavioral effects of adrenalectomy, so that performance remains unimpaired. However, perhaps more pertinent would be a study of the effects of DA-receptorblocking drugs in DNAB-lesioned rats, as these compounds produce behavioral inactivation but do not greatly alter discrimination (Tombaugh, Szostak, \& Mills, 1983). Furthermore, the hypothesis would predict that DNAB lesions would increase the incidence of discriminative errors in rats treated with DA-receptor antagonists. Preliminary evidence on this point, however, argues against this simple conclusion (Cole \& Robbins, 1984a).

\section{CONCLUSIONS}

Our main conclusions can be enumerated briefly thus: (1) DNAB lesions, in our experiments, to date have had no effects on measures of attention involving nonreversal shift, latent inhibition, blocking, or, with one important exception, distraction. (2) Such lesions impair the acquisition, but not the performance, of a conditional discrimination involving temporal frequency, in either the visual or auditory modality. (3) The results cannot be explained in terms of effects upon sensory systems, motor activity, or motivational processes. (4) DNAB lesions do not impair certain other types of learning, such as conditioned taste aversion or more simple conditional appetitive discrimination tasks. (5) The lesions impair the acquisition, but not the performance, of both on-thebaseline and off-the-baseline aversive conditioned suppression. Some of these effects are present not only 3 weeks but also 3 months following surgery. (6) DNAB lesions reduce the aversion shown by deprived rats to a novel versus familiar food in a novel open field; the animals exhibit distinct preferences instead. However, in contrast, the lesion increases the latency to make initial contact with the food. These results cannot be explained in terms of changes in the global response to novel stimuli. (7) Some of the previously reported effects of DNAB lesions to retard extinction of aversively motivated behavior may have been due to coincidental damage to subcortical NA projections arising in the VNAB. (8) Damage to the VNAB produces effects on behavior dissociable from those of DNAB lesions. (9) Certain data on the effects of distracting white noise or d-amphetamine lend support to the suggestion that the LC functions in part to preserve attentional selectivity during stress, particularly (and perhaps only) in behaviorally activating circumstances.

We should like to make a few additional points. First, we hope we have shown convincingly that despite many negative results, 6-OHDA lesions of the DNAB can have significant and reliable effects on behavior, effects which in some instances, at least, remain qualitatively similar for up to 3 months following surgery. Given that lesioning the DNAB at a point rostral to the LC spares the descending projections of this nucleus, this is perhaps one of the most direct techniques available for studying the function of the coeruleocortical NA projections. The one main drawback in neural terms is the variable, incidental damage inflicted on the A1 projection from cells of lateral tegmental NA neurons. However, it is possible to assess the likely contribution of this damage to the behavioral effects of DNAB lesions by studying separate, more selective lesions of the VNAB.

We have confirmed that the 6-OHDA DNAB lesion precipitates neurochemical recovery processes such as an increase in $\beta$-receptor binding in the neocortex. However, it has not been possible to correlate this compensatory effect at the neuronal level specifically with any form of behavioral recovery. Although we found that some of the deficits shown by DNAB-lesioned rats were not present 
over 1 year following surgery, other behavioral effects were still present 3 months postoperation. Of course, we have no idea at present of the extent to which the effects of DNAB lesions are antagonized by compensatory mechanisms from an early stage. This might be an important issue in deciding, for example, the true extent of possible learning or attentional deficits following DNAB lesions.

Another important problem lies in comparing the different ways of inducing central NA depletion, for example, using neonatal 6-OHDA or DSP-4. In the experiments reported here, we found no substantially different effects of the three treatments (one of the first experiments simultaneously compared all three). However, it should be cautioned that the behavioral deficit in question was in fact not found, and certain published differences in the effects of these treatments upon peripheal and central NA systems compel their further examination.

There are several other important directions that could be taken by this work on the function of the LC. First, of course, assessing the effects of DNAB lesions in other behavioral paradigms could lead to further elucidation of the changes already found. It would seem that a more systematic attack on the attentional paradigms is warranted, not least because of the possible dissociation between blocking and latent inhibition implied in the published results. Second, the importance of contextual aspects of conditioning should be explored. Thus, in the case of the deficit in Pavlovian conditioning observed in off-thebaseline conditioning described above, it is imperative to know whether this reflects the allocation of greater associative strength to the context or background cues by the DNAB-lesioned rats, which would perhaps indicate an altered spatial span of attention, or whether it is due to a global associative impairment, as Crow's (1968) hypothesis would imply. We have suggestive evidence to support the latter possibility, as DNAB-lesioned rats responded at the beginning of the first session with a significantly quicker latency in the off-the-baseline procedure, perhaps indicating a lack of conditioning to the background cues of the operant chamber (Figure 15) (Cole \& Robbins, 1984b).

Other experiments using DSP-4 have suggested impairments in contextual learning in a taste aversion paradigm (Archer et al., 1982), and Sara (in press) has provided some suggestive evidence linking central NA to contextual retrieval processes in memory. Indeed, the role of the coeruleocortical noradrenergic mechanisms in mnemonic processing requires an extensive reevaluation because of conflicting evidence in the literature (see Gold \& Zornetzer, 1983, for a review) and because of the claim (Mair \& McEntee, 1983) that reductions in central NA turnover are associated with the anterograde amnesia observed in cases of Korsakoff's syndrome. There has generally, however, been no suggestion that the coeruleocortical projection is involved in short-term memory, a conclusion supported by the data we reported in Table 6 .
Further behavioral dissection of the role of the LC would also be aided by more studies employing local infusion of 6-OHDA into terminal regions such as the hippocampus, amygdala, and neocortex. A potential problem here is the more rapid and complete recovery which follows such terminal infusions, partly due to collateral sprouting of spared NA neurons. Chronic infusion of 6OHDA, using osmotic minipumps, may be a possible solution to this problem for longer-term experiments (Kasamatsu, 1983).

An alternative approach is to achieve temporary, reversible reductions in coereuleal activity by microinfusion of drugs such as clonidine, which acts as an $\alpha-2$ agonist to reduce NA release from terminals, or to reduce cell body activity, depending upon the site of injection. A related approach involving infusions of the $\beta$-blocker propranolol has already been employed with success (Gallagher, Kapp, Musty, \& Driscoll, .1977). Even more promising would be to effect the activation, rather than depression, of the system, for example, by infusing $\alpha-2$ antagonists into the vicinity of the LC (Weiss et al., 1982), and to see if the resulting pattern of behavioral changes is opposite in nature to that seen following DNAB lesions. These techniques will obviously have to be used in conjunction with relatively short-term behavioral procedures, such as off-the-baseline conditioned suppression or tests of neophobia.

Finally, it is evident, particularly from our later work described here, that more detailed functional comparisons need to be made with manipulations of other important ascending pathways from the isodendritic core, or, as formerly known, the reticular formation. In particular, the contrasting actions of the ascending DA and NA projections need to be analyzec aarefully because of suggestions that, whereas the NA projections are involved in stimulus analysis and response selection, the DA projections are more involved in processes of incentivemotivation and response activation (see Robbins \& Everitt, 1982). In addition, there has been relatively little comparison of the functions of the noradrenergic and cholinergic (ACh) projections to both the neocortex and the hippocampus. It is difficult to discuss their relative functions at present, but their differing distributions within the same cortical domains may indicate complementary but distinctive actions on cortical processing.

The investigation of such important functional problems requires a comparison of the effects of manipulations of these (i.e., NA, DA, and ACh) systems where they converge into a common neocortical region such as the prefrontal cortex. It is also necessary to develop tasks employing conditions that can be used to challenge and expose the functions of the projections in different circumstances. In view of the by now well-known association of NA depletion with both Alzheimer's and Parkinson's diseases, it has become imperative not only to understand the separate functions of NA but also to characterize its interactions with the other ascending DA, serotonin (5- 
HT), and ACh projections known to be impaired in these states-and to understand the functional consequences of such interactions.

\section{REFERENCES}

Acheson, A., Zigmond, M. J., \& STricker, E. M. (1980). Compensatory increase in tyrosine hydroxylase activity in rat brain after intraventricular injections of 5-hydroxydopamine. Science, 207, 537-540.

Amaral, P. G., \& Sinnamon, H. M. (1977). The locus coeruleus: Neurobiology of a central noradrenergic nucleus. Progress in Neurobiology, 9, 147-196.

Anlezark, G. M., Crow, T. J., \& Greenway, A. P. (1973). Impaired learning and decreased cortical norepinephrine after bilateral locus coeruleus lesions. Science, 181, 682-684.

Antelman, S. M., \& Caggiula, A. R, (1977). Norepinephrinedopamine interactions and behavior. Science, 195, 646-653.

ARCHER, T., Cotic, T., \& JÄrBE, T. U. (1982). Attenuation of the context effect and lack of unconditioned stimulus-preexposure effects in taste-aversion learning following treatment with DSP4, the selective noradrenaline neurotoxin. Behavioral \& Neural Biology, 35, 159-173.

Aston-Jones, G., \& Bloom, F. E. (1981a). Activty of norepinephrine containing locus coeruleus neurons in behaving rats anticipates fluctuations in the sleep-wake cycle. Journal of Neuroscience, 1, 876-886.

Aston-JoNEs, G., \& BLOOM, F. E. (1981b). Norepinephrine-containing locus coeruleus neurons in behaving rats exhibit pronounced responses to non-noxious environmental stimuli. Journal of Neuroscience, 1 , $887-900$.

BorsinI, F., \& RolLs, E. T. (1984). Role of noradrenaline and serotonin in the basolateral regions of the amygdala in food preference and learned taste aversion in the rat. Physiology \& Behavior, 33, 37-43.

Britton, D. R., Ksir, C., Thatcher-Britton, K., Young, D., \& KоOB, G. F. (1984). Brain norepinephrine depleting lesions selectively enhances behavioral responsiveness to novelty. Physiology \& Behavior, 33, 473-478.

Carl, M., Robbins, T. W., Evenden, J. L., \& Everitt, B. J. (1983). Effects of lesions to ascending noradrenergic neurons on performance of a 5-choice serial reaction task in rats: Implications for theories of dorsal noradrenergic bundle function based on selective attention and arousal. Behavioral Brain Research, 9, 361-380.

Cole, B. J., \& RobBins, T. W. (1984a). [Effects of d-amphetamine on visual discrimination following DNAB lesions]. Unpublished raw data.

Cole, B. J., \& Robins, T. W. (1984b). [Effects of DNAB lesions on contextual learning in an off-the-baseline procedure]. Unpublished raw data.

Cole, B. J., \& Robins, T. W. (1985). Dissociable effects of cortical and hypothalamic noradrenaline depletion on the acquisition, performance and extinction of aversive conditioning. Manuscript submitted for publication.

Cole, B. J., Robbins, T. W., Jones, G. H., Dooley, D. J., \& EveritT, B. J. (1985). Lesions of the dorsal noradrenergic bundle simultaneously enhance and reduce responsivity to novelty in a food neophobia test. Manuscript submitted for publication.

Crow, T. J. (1968). Cortical synapses and reinforcement. Nature, 219 , 736-737.

Davies, D. C., HoRn, G., \& McCABE, B. J. (1985). Noradrenaline and learning: Effects of the noradrenergic neurotoxin DSP4 on imprinting in the domestic chick. Behavioral Neuroscience, 99, 652-660.

Dooley, D. J., Bittiger, H., Hauser, K. L., Bischoff, S. F., \& WALDMEIER, P. C. (1983). Alteration of central alpha $a_{2}$ and beta adrenergic receptors in the rat after DSP-4, a selective noradrenergic neurotoxin. Neuroscience, 9, 889-898.

Dooley, D. J., Jones, G. H., Cole, B. J., \& Robbins, T. W. (1984). [Longlasting effects of central NA depletion on $\beta$-receptor binding]. Unpublished raw data.

DunN, L. T., \& Everitr, B. J. (1985). The effects of lesions to noradrenergic projections from the locus coeruleus and lateral tegmental cell groups on CTA in the rat. Manuscript submitted for publication.
Everitt, B. J., Robbins, T. W., Fray, P. J., \& Gaskin, M. (1982). [Effects of DNAB lesions on visual discrimination learning]. Unpublished raw data.

Everitt, B. J., Robbins, T. W., Gaskin, M ., \& Fray, P. (1983). The effects of lesions to ascending noradrenergic neurones on discrimination learning and performance in the rat. Neuroscience, 10, 397-410.

Foote, S., Aston-Jones, G., \& Bloom, F. E. (1980). Impulse activity of locus coeruleus neurons in awake rats and squirrel monkeys is a function of sensory stimulation and arousal. Proceedings of the $\mathrm{Na}$ tional Academy of Sciences, USA, 77, 3033-3037.

Foote, S. L., Friedman, R., \& Oliver, A. P. (1975). Effects of putative neurotransmitters on neuronal activity in monkey cerebral cortex. Brain Research, 86, 229-242.

Gallagher, M., KapP, B. S., Musty, R. E., \& Driscoll, P. A. (1977). Memory formation: Evidence for a specific neurochemical system in the amygdala. Science, 198, 423-425.

GefFen, L. B., Clark, C. R., \& GeFFen, G. M. (1984). Monoaminergic innervation of cerebral cortex. In R. Bandler (Ed.), Modulation of sensorimotor activity during alterations in behavioral states (pp. 2538). New York: A. R. Liss.

Gold, P., \& Zornetzer, S. (1983). The mnemon and its juices: Neuromodulation of memory processes. Behavioural \& Neural Biology, 38, 151-159.

Gray, J. A. (1982). The neuropsychology of anxiety. Oxford: Clarendon Press.

Harik, S. I., Duckrow, H. B., La Manna, J. C., Rosenthal, M., Sharma, V. K., \& Bannerjee, S. P. (1981). Cerebral compensation for chronic noradrenergic denervation induced by locus coeruleus lesion: Recovery of receptor binding, isoproterenol-induced adenylate cyclase activity and oxidative metabolism. Journal of Neuroscience, 1, 641-649.

KASAMATSU, T. (1983). Neuronal plasticity maintained by the central norepinephrine system in the cat visual cortex. In J. M. Sprague \& A. N. Epstein (Eds.), Progress in psychobiology and physiological psychology (Vol. 10, pp. 1-112). New York: Academic Press.

Kasamatsu, T., \& Heggelund, P. (1982). Single cell responses in cat visual cortex to visual cortex to visual stimulation during iontophoresis of noradrenaline. Experimental Brain Research, 45, 317-324.

KeTY, S. S. (1970). The biogenic amines and the central nervous system: Their possible roles in arousal, emotion and learning. In F. O. Schmidt (Ed.), The neurosciences: Second study program (pp. 324336). New York: Rockefeller University Press.

Keverne, E. B., \& DE la Riva, C. (1982). Pheromones in mice: Reciprocal action between the nose and brain. Nature, 296, 148-150.

KоOв, G. F., Kelley, A. E., \& Mason, S. T. (1978). Locus coeruleus lesions: Learning and extinction. Physiology \& Behavior, 20, 709-716.

Leconte, P., \& Hennevin, E. (1981). Post-learning paradoxical sleep, reticular activation and noradrenergic activity. Physiology \& Behavior, 26, 587-594.

Lorden, J. F., Rickert, E. J., \& BerRy, D. W. (1983). Forebrain monoamines and associative learning: I. Latent inhibition and conditioned inhibition. Behavioural Brain Research, 9, 181-199.

Lorden, J. F., Rickert, E. J., Dawson, R., JR., \& PelleymounTER, M. A. (1980). Forebrain norepinephrine and the selective processing of information. Brain Research, 190, 569-573.

MaCKINTOSH, N. J. (1983). Conditioning and associative learning. Oxford: Clarendon Press.

MaIR, R. G., \& McEnTEe, W. J. (1983). Korsakoff's psychosis: Noradrenergic systems and cognitive impairment. Behavioural Brain Research, 9, 1-32.

Martin-Iverson, M. T., Pisa, M., Chan, E., \& Fibiger, H. C. (1982). Enhanced neophobia but normal plasma corticosterone levels in rats with dorsal noradrenergic bundle lesions. Pharmacology, Biochemistry \& Behavior, 17, 639-643.

Mason, S. T. (1983). The neurochemistry and pharamacology of extinction behavior. Neuroscience \& Biobehavioural Reviews, 7, 325-347.

MASON, S. T., \& Fibiger, H. C. (1979). Neurochemical basis of the dorsal bundle extinction effect. Pharmacology, Biochemistry \& Behavior, 10, 373-380. 
Mason, S. T., \& Iversen, S. D. (1979). Theories of dorsal bundle extinction effect. Brain Research Reviews, 1, 107-137.

Mason, S. T., \& LiN, D. (1980). Dorsal noradrenergic bundle and selective attention. Journal of Comparative \& Physiological Psychology, 94, 819-832.

Mason, S. T., Roberts, D. C. S., \& Fibiger, H. C. (1978). Noradrenaline and neophobia. Physiology \& Behavior, 21, 353-361.

Meck, W. H., Сhurch, R. M., \& Olton, D. S. (1984). Hippocampus, time and memory. Behavioral Neuroscience, 98, 3-22.

Mohammed, A, K., ArCher, T., \& JärBE, T. U. C. (1984). Noradrenaline loss and the disruption of between-CS stimulus generalisation effects in aversion learning. Scandinavian Journal of Psychology, 25, 79-88.

Mohammed, A. K., Everitt, B. J., Dunn, L. T., Robbins, T. W., KILBourn, A., \& ARCHER, T. (1983). Noradrenaline and the latent inhibition effect in rats [Abstract]. Proceedings of the Fifth Catecholamine Symposium, Göteborg, Sweden. In Progress in Neuropsychopharmacological \& Biological Psychiatry.

Mohammed, A. K., Järbe, T., Archer, T., Robbins, T. W., \& EveritT, B. J. (1984). [Comparative effects of DSP-4, neonatal 6OHDA and DNAB lesions on latent inhibition in a CTA paradigm]. Unpublished raw data.

Morrison, J. H., \& Magistretti, P. J. (1983). Monoamines and peptides in cerebral cortex. Trends in Neuroscience, 6, 146-151.

Ögren, S., \& FuXE, K. (1974). Learning, noradrenaline and the pituitary-adrenal axis. Medical Biology, 52, 399-405.

Owen, S. R., Boarder, M., Gray, J. A., \& Fillenz, M. (1982). Lesions of the dorsal noradrenergic bundle and rewarded running: The role of pre-training. Behavioural Brain Research, 5, 3-9.

PISA, M., \& Fibiger, H. C. (1983a). Evidence against a role of the rat's dorsal noradrenergic bundle in selective attention and place memory. Brain Research, 272, 319-329.

PISA, M., \& Fibiger, H. C. (1983b). Intact selective attention in rats with lesions of the dorsal noradrenergic bundle. Behavioral Neuroscience, 97, 519-529.

REDMOND, D. E. (1979). New and old evidence for the involvement of a brain norepinephrine system in anxiety. In W. G. Fann, I. Karacan, D. Pokorny, \& R. L. Williams (Eds.), Phenomenology and treatment of anxiety (pp. 153-203). New York: Spectrum.

RobBins, T. W. (1984). Cortical noradrenaline, attention and arousal. Psychological Medicine, 14, 13-21.

RobBins, T. W., \& EveritT, B. J. (1982). Functional studies of the central catecholamines. International Review of Neurobiology, 23, 303-365.

RobiINs, T. W., \& EveritT, B. J., (1983). [Effects of DNAB lesions on blocking in an appetitive situation]. Unpublished raw data.

Robbins, T. W., Everitt, B. J., Fray, P. J., \& Gaskin, M. (1983). [Effects of DNAB lesions on delayed discrimination and non-reversal shift performance]. Unpublished raw data.

Robbins, T. W., Everitt B. J., Fray, P. J., Gaskin, M., Carli, M., \& DE LA RIVA, C. (1982). The roles of the central catecholamines in attention and learning. In M. Y. Spiegelstein \& A. Levy (Eds.), Behavioral models and the analysis of drug action (pp. 109-134). Amsterdam: Elsevier.

Robiins, T. W., \& Sahakian, B. J. (1983). Behavioral effects of psychomotor stimulant drugs: Clinical and neuropsychological implications. In I. Creese (Ed.), Stimulants: Neurochemical, behavioral and clinical perspectives (pp. 301-338). New York: Raven Press.

Roberts, D. C. S., Price, M. T. C., \& Fibiger, H. C. (1976). The dorsal tegmental noradrenergic projection: An analysis of its role in maze-learning. Journal of Comparative \& Physiological Psychology, 90, 363-372.

Ross, S. B. (1976). Long term effects of N-2-chloroethyl-N-ethyl-2bromobenzylamine hydrochloride on noradrenergic neurones in the rat brain and heart. British Journal of Pharmacology, 58, 521-527.

Sahakian, B. J., WinN, P., Robbins, T. W., Dooley, R. J., Everitt, B. J., Dunn, L. T., Wallace, M., \& James, W. P. T. (1983). Changes in body weight and food-related behaviour induced by destruction of the ventral or dorsal noradrenergic bundle. Neuroscience, 10, 1405-1420.

SARA, S. (in press). Noradrenergic modulation of selective attention: Its role in memory retrieval. Annals of the New York Academy of Science.

Sawchenko, P. E., \& Swanson, L. W. (1981). Central noradrenergic pathways for the integration of hypothalamic neuroendocrine and autonomic responses. Science, 214, 685-687.

SEgal, M., \& Bloom, F. E. (1976). The action of norepinephrine in the rat hippocampus. IV. The effects of locus coeruleus stimulation on evoked hippocampal activity. Brain Research, 107, 513-525.

Sutherland, N. S., \& Mackintosh, N. J. (1971). Mechanisms of animal discrimination learning. London: Academic Press.

Sutherland, R. J., Kolb, B., Whishaw, I. Q., \& Becker, J. B. (1982). Cortical noradrenaline depletion eliminates sparing of spatial learning after neonatal frontal cortex damage in the rat. Neuroscience Letters, 32, 125-130.

Tombaugh, T. N., Pappas, B. A., Roberts, D. C. S., Vickers, G. J., \& SzostaK, C. (1983). Failure to replicate the dorsal bundle extinction effect: Telencephalic norepinephrine depletion does not reliably increase resistance to extinction but does augment gustatory neophobia. Brain Research, 261, 231-242.

Tombaugh, T. N., Szostak, C., \& Mills, P. (1983). Failure of pimozide to disrupt the acquisition of light-dark and spatial discrimination problems. Psychopharmacology, 79, 161-168.

Tsaltas, E., Gray, J. A., \& Fillenz, M. (1984). Alleviation of response suppression to conditioned aversive stimuli by lesions of the dorsal noradrenergic bundly. Behavioural Brain Research, 13, 115-127.

Tsaltas, E., Preston, G. C., Rawlins, J. N. P., Winocur, G., \& GraY, J. A. (1984). Dorsal bundle lesions do not affect latent inhibition of conditioned suppression. Psychopharmacology, 84, 549-555.

U'Prichard, D. C., Reisine, T. D., Mason, S. T., Fibiger, H. C., \& YAMAMURA, H. I. (1980). Modulation of rat brain alpha- and betaadrenergic receptor populations by lesions of the dorsal noradrenergic bundle. Brain Research, 187, 143-154.

Watabe, K., NAKaI, K., \& Kasamatsu, T. (1982). Visual afferents to norepinephrine-containing neurones in cat locus coeruleus. $E x$ perimental Brain Research, 48, 66-80.

WATERHOUSE, B. D., \& WoODWARD, D. J. (1980). Interaction of norepinephrine with cerebro-cortical activity evoked by stimulation of somatosensory afferent pathways. Experimental Neurology, 67, 11-34.

Weiss, J. M., Bailey, W. H., Goodman, P. A., Hoffman, L. J., Ambrose, M. J., Salmon, S., \& Charry, J. M. (1982). A model for neurochemical study of depression. In M. Y. Spiegelstein \& A. Levy (Eds.), Behavioral models and the analysis of drug action (pp. 195233). Amsterdam: Elsevier.

(Manuscript received July 8, 1985; revision accepted for publication October 24,1985 .) 